\title{
Reference Database Marine Mammal Literature
}

\author{
by \\ William A. Watkins, James E. Bird*, Karen E. Moore, \\ and Peter Tyack \\ Woods Hole Oceanographic Institution \\ Woods Hole, Massachusetts 02543 \\ *McKeldin Library, University of Maryland \\ College Park, Maryland 2.0742 \\ January 1988
}

\section{Technical Report}

Support for beginning work on the Database was by The Marine Mammal Commission and by

The National Marine Fisheries Service

Reproduction in whole or in part is permitted for any purpose of the United States Government. This report should be cited as:

Woods Hole Oceanog. Inst. Tech. Rept., WHOI-88-2

Approved for publication; distribution unlimited.

Approved for Distribution:

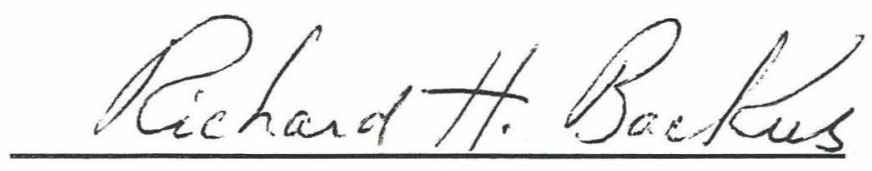

Richard H. Backus, Chairman

Department of Biology 



\begin{abstract}
A comprehensive Reference Database has been designed for the marine mammal literature. The system uses INMAGIC programming (Cambridge, MA) to file, store, search, retrieve, and format the data records. The database was organized to be complementary to features developed by William E. Schevill for his library of older cetacean literature, and it uses direct association of species with some 300 indexed subjects, observation dates, locations, etc. Every component and detail of the references and annotations are available for rapid search by a wide variety of simple and complex strategies. In addition, separately indexed fields provide immediate retrieval of author, editor, year, journal, type of publication, language, genus/species (searchable by order/suborder and family as well), major subject, subject, picture, observation date, geographic location (including area name and latitude/longitude), as well as the location and library call numbers of the document referred to. Codes have been adapted for ease in identifying and searching species, subjects, journals, languages, and geographic areas. These codes may be used separately or in connection with the associated terms and texts. It is anticipated that the Reference Database will be a continuing resource for marine mammal research.
\end{abstract}





\section{Reference Database -- Page 1 CONTENTS}

Introduction to the Reference Database ------------- Page 2 Equipment Requirements for using the Database --------- 4 Start Using the Database and INMAGIC Program $---\infty$ Searching the Reference Database - 7 Organization of the Database Records - 9 List of Database Fields -------------------------- 10 Record Number -- RECNO - 13 Title of Journal or Volume -- SOURCE --- 13 Journal Identification Code -- CODEN -Picture -- PICTU -

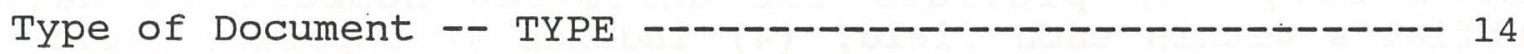
Language Code -- LANGU Geographic Areas Map --Geographic Location Code -- GEOA Geographic Location Names -- GEOB --- - - Latitude and longitude -- GEOC -------------------- 18 Location of the Document -- LOCATE -- 18 Data Structure for Reference Database --------------- 19 Database Record Entries Format of Printed Records Organization of the Species List LIST OF SPECIES AND THEIR CODES SUBJECT HEADINGS AND THEIR CODES ALPHABETICAL LIST OF SUBJECT HEADINGS AND CODES NUMERICAL LIST OF SUBJECT HEADING CODES 


\section{Reference Database -- Page 2}

Introduction to the Reference Database --

The Reference Database has been organized to create a flexible and searchable compilation of marine mammal literature references. The database was designed to be complementary to the features developed by W. E. Schevill for his collection of the older cetacean literature. The database also has evolved to fit the capabilities of available computer information systems. It has benefitted by comparisons with other specialized literature collections. The result is a relatively simple, easily searched reference database. It features direct association of species to indexed subjects, with every component or alphanumeric entry in the record available for searching by a wide variety of simple and complex strategies. The database is used with PC computers (IBM compatible) with INMAGIC software (INMAGIC Inc., Cambridge, MA), either with only two floppy-disk drives using smaller numbers of references, or with hard disk memory for larger numbers of references. See requirements listed below.

The Reference Database (1) permits records of any length, (2) allows up to 75 user-defined fields (current database uses about 25), (3) provides for unlimited numbers of defined subfields within each field, (4) indexes 40 separate fields (in addition to the indexing of subfields within this structure), (5) indexes immediately as each data record is entered, (6) allows independent sorting of each of the fields or subfields, (7) supports search strategies developed with Boolean operators (and, or, not) and nested arguments, (8) permits searches limited by qualifiers (greater than, less than, equal to, from/to), (9) provides for convenient right-hand truncation in search statements, (10) saves and combines search results, (11) allows a wide variety of user-defined formats for display or reordering of data, (12) prints any number of selected records in any of these formats, (13) lists any of the indexed terms or fields with their frequency of occurrence, and (14) permits the use of extended characters (italics, foreign language) in printing records, (15) provides for the development of flexible on-line thesaurus of terms, search operators, and definitions for help in searching the records, (16) permits rapid copying of data records to standard ASCII files (for use with other databases, or manipulation with word processing programs), (17) allows importation of ASCII records created elsewhere.

The Reference Database for marine mammal literature allows rapid, very detailed searches by author, editor, year, journal, type of publication, language, genus/species (searchable by order/suborder and family as well), major subject, subject, picture, geographic locations (including area names and latitude/longitude), as well as the location of the document that is referred to. Species can be connected directly 
Reference Database -- Page 3

to subjects and locations. Terms, and text words including stems of words or partial phrases and parts of alphanumeric entries may be used in searching. In addition, codes have been adapted for ease in identifying and searching species, subjects, journals, languages, and geographic areas. These codes may be used separately or in connection with the associated terms and text.

The organization of the model for the database was by William E. Schevill. Comparisons and assessments of data management software suitable to this organization of literature references was largely by Karen E. Moore. Adaptation of the reference database requirements to the INMAGIC program was mostly by James E. Bird. General oversight of computer handling of the database and program interactions has been by Peter $L$. Tyack. William A. Watkins has been responsible for the current format, compilation, and general documentation of the database. Barbara $E$. Rosenheck has the oversight of current data entries. It is our hope that this Reference Database will be a continuing resource for marine mammal research.

Funding for the beginning components of the Reference Database for marine mammal literature has been provided by woods Hole Oceanographic for laboratory support, Marine Mammal Commission (MM4465702-4) for the INMAGIC program software and additional computer memory, and the National Marine Fisheries Service (40EANF702277) for the beginning database entries. 
Reference Database -- Page 4

Equipment Requirements for the Reference Database --

The Reference Database has been configured for convenient use in the marine mammal bioacoustics laboratory at the woods Hole Oceanographic Institution. However, the INMAGIC software is available for a considerable range of computers (from the Wang PC to DEC VAX).

We use the following arrangement:

(1) IBM compatible PC computer. Our current system uses Compaq computers with MS-DOS 2.12 operating system. The INMAGIC program is used on a computer with (A) two disk drives and at least $256 \mathrm{~K}$ memory, or (B) on a computer with a hard disk. (see start INMAGIC below).

(2) INMAGIC (XXMAGIC for extended characters) software to run and maintain the reference database -- INMAGIC, INC., 238 Broadway, Cambridge, MA 02139, Phone (617) 661-8124. Cost for the software varies with the number of units, the first one was over $\$ 800$, but group rates and discounts for 25 units would bring the price down to about $\$ 300$.

(3) Copy of the data records for the Reference Database. The database has been configured to be used with either a PC computer with dual disk-drives alone or with a hard disk. We anticipate that copies of data files could be made available on standard floppy disks. The size of the database limits convenient use with just the floppy-disks, however, the database may be divide and used in smaller components, for example, species groups. See following section on "INMAGIC start" for details of beginning, and operational procedures.

(4) A printer is needed to print references and the search results. A dot-matrix or "laser" printer is needed for use with extended characters. 


\section{Reference Database -- Page 5}

Start Using the Database and INMAGIC Program --

A brief introduction to entering and using the Marine Mammal Reference Database and the INMAGIC program.

Two forms of the INMAGIC program are currently in use at WHOI with the Reference Database for PC computers (IBM compatible); one for a computer with a hard disk containing much or all of the database, and a second with the program installed on dual floppy-disks (5.25-inch) containing smaller numbers of references.

HARD DISK:

(1) Turn on the hard disk (if separate from computer).

(2) Turn on the computer (with disk drives open).

(3) Bring up the INMAGIC sub-directory (XXMAGIC is the 8-bit IBM extended-character version of INMAGIC in use at WHOI).

(4) Choose SELECT from the INMAGIC Main Menu for searching the Database, selecting references, and printing selections.

or - Choose MAINTAIN from the Main Menu for working within the Database to edit or add to the records.

(5) When requested, type the current filename to enter the database (for example, CETACEAI). The temporary work file can be named anything (up to 8 characters).

(6) To leave the current work, abandon any changes, and return to a menu, type [ $\mathrm{Ctrl/C}]$ [RET]. To save the work that has been changed or added, press the [F2] key. For exit from menus, type $\underline{E}$ [Ret]

(7) CAUTION: ALWAYS RETURN TO MAIN MENU BEFORE LEAVING INMAGIC -- otherwise, the database could be harmed.

FLOPPY-DISKS :

(1) In drive A, insert XXMAGIC system Disk (\#1 Boot).

(2) In drive B, insert XXMAGIC Program Disk (\#2 Program).

(3) Turn on computer -- both disks will be loaded into the computer. The \#I system disk will remain in drive A.

(4) Remove \#2 Program disk from drive B and replace with the Data disk containing record files (CETACEAl, for example).

(5) Choose SELECT from the INMAGIC Main Menu for searching the Database, selecting references, and printing selections.

Or - Choose MAINTAIN from the Main Menu for working within the Database to edit or add to the records.

(6) When requested, type the drive and current filename to enter the database (for example, B:CETACEAI). The temporary work file can be named anything (up to 8 characters).

(7) To leave the current work, abandon any changes, and return to a menu, type [ $\mathrm{Ctrl} / \mathrm{C}]$ [ $\mathrm{RET}]$. To save the work that has been changed or added, press the [F2] key. Type E [Ret] for exit from menus.

(8) CAUTION: ALWAYS RETURN TO MAIN MENU BEFORE LEAVING INMAGIC -- otherwise, the database could be harmed. 


\section{Reference Database -- Page 6}

To return to the database from DOS, repeat the process, indicating the drive (path) and program as needed. For use with floppy-disks: put \#1 System disk in drive $A$ and \#2 Program disk in drive B, and then type B:XXMAGIC. At the Main Menu, replace \#2 Program disk in drive $B$ with the Data disk, and when requested, type the filename (such as, B:CETACEA1) to access the database.

For work within the Reference Database, choose MAINTAIN at the Main Menu. Then, to add new records or modify existing records, choose COMPOSE from the MAINTAIN menu. The retrieval code (record number, RECNO) will identify the record to be modified, or number a new record to be entered. The current record or a blank new record format will be displayed, with all fields names indicated in appropriate order. Entry of changes or of new data is straight forward (refer to INMAGIC program manual for details of editor functions, etc.) Entries may be made at each field prompt (preassigned and named by the Data Structure: CITA, YEAR, AUTHOR, EDITOR, etc.). The line of text will automatically wrap to the next line within fields, and subfields are easily added with the use of the Flo key. Additional subfields accommodate different search terms that can be indexed, such as when the record contains more than one author (or editor, genus/species, subject, geographic location, etc.). For example, after the complete citation has been entered, searchable fields are specified for each author, the first author in the AUTHOR/1 subfield (label AU/1), second author in the AUTHOR/2 subfield, third in the AUTHOR/3 subfield, etc. Movement to other fields is by the [RET] key or by the arrow keys, with conventional cursor movement. Deletions are by the [DEL] key which back-spaces as it deletes. Changes or additions can be repeated as often as desired. The completed record is saved by pressing the [F2] key, and INMAGIC automatically indexes and sorts the fields as the record is added to the Reference Database. 


\section{Reference Database -- Page 7}

Searching the Reference Database --

There are relatively simple ways to find any alphanumeric notation in any portion of a reference of the database. The most rapid searches are of the indexed fields. The database may be searched with a variety of simple and complex search strategies. Search results may be sorted, displayed, and printed in a wide variety of formats defined by the user as desired. See INMAGIC manual for details of strategies, commands, and relationships for searching the database.

To search the Reference Database and select particular references, choose SELECT at the Main Menu. If not already identified, indicate the filename and path for the database records (for example, CETACEAI or B:CETACEAl as in section on Start INMAGIC, page 5) and identify a temporary work file (up to 8 characters). The propmt (*) is then displayed to indicate that the INMAGIC program is ready to search the database.

Help information about search commands and relationships are available by pressing the Return [Ret] key (see below), providing rapid reminders of such commands as GET and DISPLAY. Search commands may be combined with search relations such as

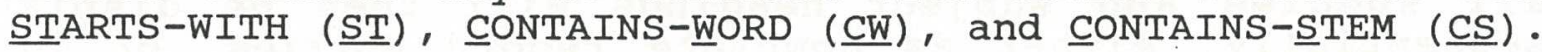

The LIST command will list the contents of searchable (indexed) fields in the database, for example, of authors $(\underline{\underline{A U}})$, editors ( $\underline{\underline{E} \underline{E D})}$, subjects ( $\underline{\underline{S}} \underline{\mathrm{SJ}})$, or geographic location ( $L$ GA) to provide an alphabetical list of all authors (or editors, subject headings, geographic locations, etc.) in these fields of the reference database. This list may be limited by combining with alphanumeric search relations such as STARTS WITH (ST) or FROM..TO. Notations given in the results of this list are prefaced by a number representing their occurrence in that field of the database.

\begin{tabular}{|c|c|c|}
\hline GET & - start a new search & - describe new search \\
\hline AND & - narrow the search (inclusion) & - re-enter old search \\
\hline MOT & - narrow the search (exclusion) & - re-execute old search \\
\hline OF: & - troaden the search & $\begin{array}{l}\text { - save search resubts } \\
\text { - erase stored search }\end{array}$ \\
\hline DISFLAYY & - show results an screen & - show stored searches \\
\hline FFIINT & - print results in report & \\
\hline WFITE & .. place results in outside file & $\begin{array}{l}\text { STRUCTUFE - show data structure } \\
\text { LIST - show keys in inder }\end{array}$ \\
\hline $\begin{array}{l}\text { TEACH } \\
\text { EXIT }\end{array}$ & $\begin{array}{l}\text { - display tutorial } \\
\text { - return to MAIN menul }\end{array}$ & - show disk directury \\
\hline $\begin{array}{l}\text { For addi } \\
\text { also ava } \\
\text { Bu } \\
\text { WO } \\
C Q\end{array}$ & 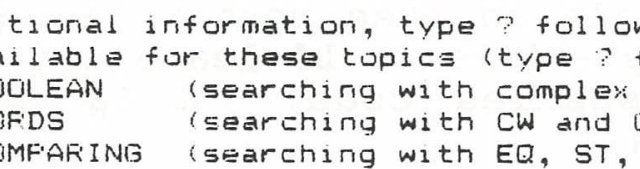 & $\begin{array}{l}\text { wed by name of command. Help is } \\
\text { followed by topic): } \\
\text { commands) } \\
\text { CG relations) } \\
\text { GT, GE, LT, LE, FFOM..TO) }\end{array}$ \\
\hline
\end{tabular}




\section{Reference Database -- Page 8}

Each Subject Heading used in the database is tied directly to species by a code assigned to each subject and each species, so that a LIST of the SUBJECT field ("L SJ") of a portion of the database might produce the following result:

3 FEEDING $404 \mathrm{AB} 1 \mathrm{~A}$

2 FEEDING 404AB1A 404AC2A

1 INTELLIGENCE 545AB1A

This list indicates three records were found on feeding (code 404) by Eschrichtius robustus (code ABIA), two records on feeding in both E. robustus and Megaptera novaeangliae (AC2A), and one record on intelligence (code 545) in E. robustus.

A search statement using the GET command may be used to locate particular records. For example, for records discussing cetacean pigmentation, the search statement could be as follows: $\underline{G} \underline{\mathrm{SJ}} \underline{\mathrm{CW}}$ PIGMENTATION (GET SUBJECT CONTAINS-WWORD PIGMENTATION). The result of this search might be this:

FOUND 6 PIGMENTATION IN SUBJECT

[Search] \# 1 NUMBER OF RECORDS :6

The result of this search \#1 can then be seen by using the DISPLAY command at the ready prompt $(*):$ D \#1 (DISPLAY search \#1). Each of these complete references (records) with all species and subject headings will then be displayed, sequentially, either as complete record entries, or in any selected format with the information re-arranged. The original information used for the search statement will be highlighted.

If a paper by Schevill on pigmentation (code 233) in E. robustus (code $\mathrm{AB} 1 \mathrm{~A}$ ) were desired, that particular record could be selected by including the AUTHOR field in the search: $\underline{G} \underline{A U}$ CW SCHEVILL $\underline{A}$ SJ CW $233 \mathrm{ABIA}$ (GET AND SUBJECT CONTAINS-WORD 233ABIA). If the year of publication were known to be 1980, then the search could be narrowed further by adding the YEAR field to the search: $\underline{G} \underline{A U}$ CW SCHEVILL $\underline{A} \underline{Y R}$ CW 1980 A SJ CW 233ABIA (GET AUTHOR CONTAINS-WEORD SCHEVILL AND YEAR CONTAINS-WWORD 1980 AND SUBIECT CONTAINS-WORD 233ABIA)。

The design of the database takes advantage of INMAGIC's right hand truncation. For example, to find records specifically on feeding in Balaenoptera edeni, the search statement could use the codes for feeding and $B_{0}$ edeni, like this: $G$ SJ $\underline{C W}$ 404ACIC (GET SUBJECT CONTAINS-WORD $404 \mathrm{ACIC}$ ). A less specific search for feeding in rorquals generally could leave off the last character of the species code and use the search relation CS (CONTAINS STEM): G SJ CS $404 A C I$ (GET SUBJECT CONTAINS-STEM $404 A C I)--404$ is the code for feeding and AC1C the code for $\underline{B}$. edeni. While an even more more general search for feeding in the Balaenopteridae could leave off the last two characters of the genus/species code: $\underline{G} \underline{\mathrm{SJ}} \underline{\mathrm{CS}}$ 404AC (GET SUUBIECT CONTAINS- STEM $\underline{404 A C)}$. 
Reference Database -- Page 9

Organization of the Database Records --

The entries in each record of the Reference Database are organized for convenience in making the entries, in searching of the indexed fields, and in reorganization of the references for display or printing:

Each record is given a unique number (RECNO).

The complete citation is entered in a standard bibliographic format.

Separate fields are used for entering author, year, title, source, publisher, etc. to allow reordering of the citation for printing and for separate indexing of some fields for rapid field searches.

Codes for journal, type of publication, and language are indicated.

Genus/species names and alphanumeric codes are entered for all species in the reference -- order/suborder, family, genus, and species are indicated in each code.

Major subject (separate field), and any number of additional subjects (another field with subfields) are entered and directly related to species by using the subject and species codes.

Pictures that are important in the document are noted and related to subject and species by the codes.

Date of observations are indicated and associated with species by the codes.

Geographic locations are indicated by area code, geographic name, and latitude/longitude when appropriate. These are all related to species by the codes.

Notes, and annotations may be included, and are related to species.

Location of the specific document (reprint, book, journal, etc.) and call numbers for particular collections or libraries are indicated.

Most fields in the records are indexed and may be searched separately to provide very rapid selection of these records. Fields such as citation (CITA) and notes (NOTES) are not indexed, but these too may be searched for any words, sentences, or alphanumeric combination. A search of non-indexed entries is much slower.

A list of "Subject Headings" and "Species" with their codes are provided to assist in establishing search relationships. 
Reference Database -- Page 10

List of Database Fields --

The entries for each reference are recorded in fields that are indexed and stored in the database. Each field is given a name and a shorter label. The field order within the database structure is pre-defined and assigned index, sort, and emphasis codes for the Reference Database (see Data Structure, p 19). A brief description is given below for each field in the record structure for the Reference Database:

Field name (label) -- description:

RECNO ( $\underline{R N}$ ) -- Record number is a unique number given to each record in the database. This number serves as a retrieval key for that particular record. This field is indexed.

CITA ( $\mathrm{CI}$ ) -- Full reference citation is given in a standard format. Authors' last names are given first and capitalized.

AUTHOR ( $\underline{\mathrm{AU}})$-- Each author (last name first) is listed in a separate subfield in the order that they appear on the document. This field is indexed.

YEAR (YR) -- Year of publication. This field is indexed.

DATE (DA) -- Additional information about publication date of the document, such as month. Also, the modification date of the record entry ("Mod" month and year, in parentheses) of the last changes to a record are put in this field to facilitate recognition of the latest database changes.

TITLE (TI) -- Title of the document.

SOURCE ( $\underline{\mathrm{SO}}$ ) - Full journal name or title of edited volume containing the document.

VOLUME ( $(\underline{L})$-- Volume and series of journal or number of report.

ISSUE (IS) -- Issue and "part" number of journal containing the document.

PAGES ( $\underline{\text { PP }}$ ) - Pagination of the document. In documents which contain intervening, unrelated pages, only the pages of the document are entered.

EDITOR (ED) -- Each editor is listed (last name first) in a separate subfield in the order that they appear on the document. This field is indexed.

EDITON (ET) -- Edition of publication is noted if 2 nd or later. 


\section{Reference Database -- Page 11}

PUBCO ( $\underline{\text { PC }}$-- Publishing company name includes the full name (for example, University of California Press). Not applicable to serials.


country, with two-letter abbreviations for the states of the U.S. Not applicable to serials.

CODEN ( $\underline{\mathrm{CO}})^{--}$Coden is a standardized alphanumeric code for journals (Biosciences Information Service). This field is indexed.

TYPE (TY) -- Type of record is indicated by letter code (journal, book, report, -- see list of record types). This field is indexed.

LANGU ( $\underline{\mathrm{LG}}$ ) -- Language of the document (see language code list). This field is indexed.

GENSP (GS) -- Genus/Species include the scientific names of genera and species, with alphanumeric codes which include order/suborder and Family. See section on organization of the species list. This field is indexed.

TAXO ( $\underline{\mathrm{TX}}$ ) -- Taxonomy notes and genus/species names used by the author which are synonyms of current names.

SUBMJ ( $(\underline{S M})$-- Major subject of the document is entered in this field. See List of Subject Headings. Species are never subjects, but are tied to subjects by code. This field is indexed.

SUBJ ( $\underline{\mathrm{SJ}})$-- Subjects are assigned to the document, and listed in separate subfields. The major subject is repeated in this list. see List of subject Headings. species are never subjects, but are tied to subjects by code. This field is indexed.

PICTU (PI) -- Pictures of note are indicated, including good drawings and photographs of activities by different species (subjects and species are indicated). This field is indexed.

OBSDATE (OD) -- Date (year and month) of the field observation of the animals reported in the document is directly associated with species by the codes. Year and month are entered separately to allow searching the year and month separately (for example an entry for a gray whale sighting on 10 Oct 1910: 1910AB1A OCTAB1A). To avoid confusion between year and month of different sightings, these should be searched separately. This field is indexed. 


\section{Reference Database -- Page 12}

GEOA (GA) -- Geographic location A uses the sea area code from Aquatic Sciences and Fisheries Information System's Geographic Authority List. The species code is appended to the location code. This field is indexed.

GEOB (GB) - Geographic location B is the name of the area or body of water, at times associated with land. This field is indexed.

GEOC (GC) - Geographic location $C$ is the latitude and longitude in degrees. The species code is appended to each latitude and longitude to allow separate searches that define an area. This field is indexed.

NOTES ( $(\underline{N T})$-- Notes on the content of the document appear in this field.

LOCATE (LO) -- Location of a copy of the document is noted if appropriate. Filing numbers and subjects of the documents in various collections are indicated along with call numbers. Library of Congress numbers are also given. This field is indexed, see further description (page 18).

Most records of the Reference Database will not have entries in all of these fields, and only those records that have information will be displayed (in SELECT). However, the entire data structure is available (in MAINTAIN) for editing or entering new information.

The last two fields (listed below) represent a special use of the database for on-line help. They include a thesaurus of subject headings and species names, with their codes, to be used in searching the Reference Database. These two fields will never appear in the list of field entries for a specific document, but they are separate documents that may be accessed from the database (by selecting the QUEST and/or DEFINE fields for searching).

QUEST (QU) -- Question: this field contains subject headings and their appropriate synonyms, as well as scientific names of species. This field is indexed.

DEFINE (DF) -- Define: this field contains definitions of subjects, helps, and sample search strategies. 
Comments on Specific Fields --

RECNO -- Record Number (label RN) -- The record number is unique to each record, and is assigned as the entry is made to serve as a retrieval code for that record. Record numbers generally are not related to any other aspect of the references. The exception is the collection of older literature by $W$. $E$. Schevill in which his document numbers have been retained as the identifying record numbers (1 to approximately 3200). These record numbers are noted on the copies of the documents in local libraries.

SOURCE -- The SOURCE field (label so) is not indexed, but provides the full title of the journal or volume for use in compilation of print formats. Indexing of Journals is provided by the CODEN.

CODEN -- Journal identification code (label CO) -- Journals are identified by a six-character identifier (such as JCRSEK for the Journal of Coastal Research) assigned by the International CODEN Service (Chemical Abstracts Service, P.O. Box 3012, Columbus, $\mathrm{OH}$ 43210). This field is indexed so that a record can be found if, for example, only the subject and journal name are known. A list of journals and their corresponding CODEN is given in "Serial sources for the BIOSIS Data Base" published by Biosciences Information Service, Philadelphia, PA 19103, on file with the Reference Database.

PICTU -- The picture field (label PI) is indexed and related to subjects and species by means of the alphanumeric codes. This field allows searching the database for documents which contain accurate, clear photos, drawings, or diagrams of marine mammals and related subjects. For whales, this could include ventral views, aerial displays, underwater photos, parasites, feeding activity, pigmentation patterns, prey species, diagnostic photos of skulls, stranded animals, fetuses, etc. For example, a photograph of a feeding humpback whale would be entered in the Picture field (PICTU) with both the subject and species codes, 404 (feeding) and AC2A (Megaptera novaeangliae). 
Reference Database -- Page 14

TYPE -- Document type (label TY) is a letter code based on the Aquatic Sciences and Fisheries Information system (ASFIS). These include codes that indicate Document Type, Bibliographic Level, and Literary style. References may have more than one code for document type:

B Monographs, non-serial documents, complete when issued.

$\mathrm{H}$ Sound recordings (phonograph records, audio cassettes and tapes, etc.).

J Journal (serial) publication, from refereed scientific journals.

$\mathrm{K}$ Conference proceedings or meeting reports. Also includes abstracts of papers presented at or submitted to conferences or meetings. (eg. individual abstracts from the biennial conferences on the biology of marine mammals) (excludes IWC documents). Mostly not published.

I Papers from edited, published scientific volumes (such as from Winn \& Olla, 1972. Behavior of Marine Animals, Current Perspectives in Research).

M Unpublished papers, such as typescripts of papers submitted for publication, student reports, etc.

I IWC documents. Includes all IWC documents, whether published in IWC volumes (special issues, annual reports, etc.) or submitted to the scientific committee and never published.

P Popular publications (articles or books).

Q Training manuals and other documents written primarily for training programs, such as P. M. Payne's marine mammal and seabird observer training manual for NMFS.

R Scientific and technical reports (NTIS, MMS, NOSC, OCSEAP, AEWC, NMFS, WHOI etc. -- the so-called "gray" literature).

U Dissertations, theses, or other treatises written to qualify for a university or other type of degree ( $p .19$, ASFIS)。

W Laws, statutes, regulatory reports, including Marine Mammal Commission annual reports.

Z Bibliographies, or documents primarily for literature citations, used only to indicate bibliography as the important part of the text (p. 19 ASFIS). 


\section{Reference Database -- Page 15}

LANGU -- Language codes (label LG) for the Reference Database are adapted from the two-letter codes used by the Aquatic Sciences and Fisheries Information system (ASFIS) with the following exceptions:

(1) No code is used for documents in English.

(2) "X" is prefixed to the two-letter language codes for documents in other languages (except English). For example, the code for Russian is XRU.

(3) "Y" is added to the two-letter language code to indicate an abstract or summary in another language (YEN would be used for an English language abstract). For example, a Russian language document with an English abstract has the following code: XRU YEN. Abstracts in other languages also use the "Y" plus the two-letter code for that language.

Thus, no entry is needed for the majority of references which are in English, but the database can be searched for English language papers by using the negative search relation --

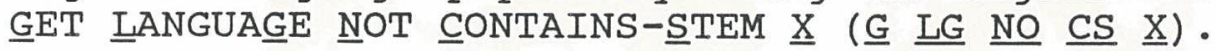

Language codes refer only to the document at hand. English translation of papers published in other languages have the blank (English) code, but the CITATION (CITA) field will indicate the original language of the paper and its original publication.

Language codes for the Reference Database are as follows:

$\begin{array}{ll}\text { XAF Afrikaans } & \text { XJA Japanese } \\ \text { XAR Arabic } & \text { XKO Korean } \\ \text { XCH Chinese } & \text { XLA Latin* } \\ \text { XCS Czech } & \text { XNL Dutch } \\ \text { XDA Danish } & \text { XNO Norwegian } \\ \text { XDE German } & \text { XPL Polish } \\ \text { XEE Estonian } & \text { XPT Portuguese } \\ \text { XES Spanish } & \text { XRU Russian } \\ \text { XFI Finnish } & \text { XSV Swedish } \\ \text { XFR French } & \text { XTR Turkish } \\ \text { XIC Icelandic* } & \text { YEN English abstract } \\ \text { XIT Italian } & \end{array}$

*IC and LA are not recognized ASFIS codes 
Reference Database -- Page 16

ASFIS Map of Geographic Areas

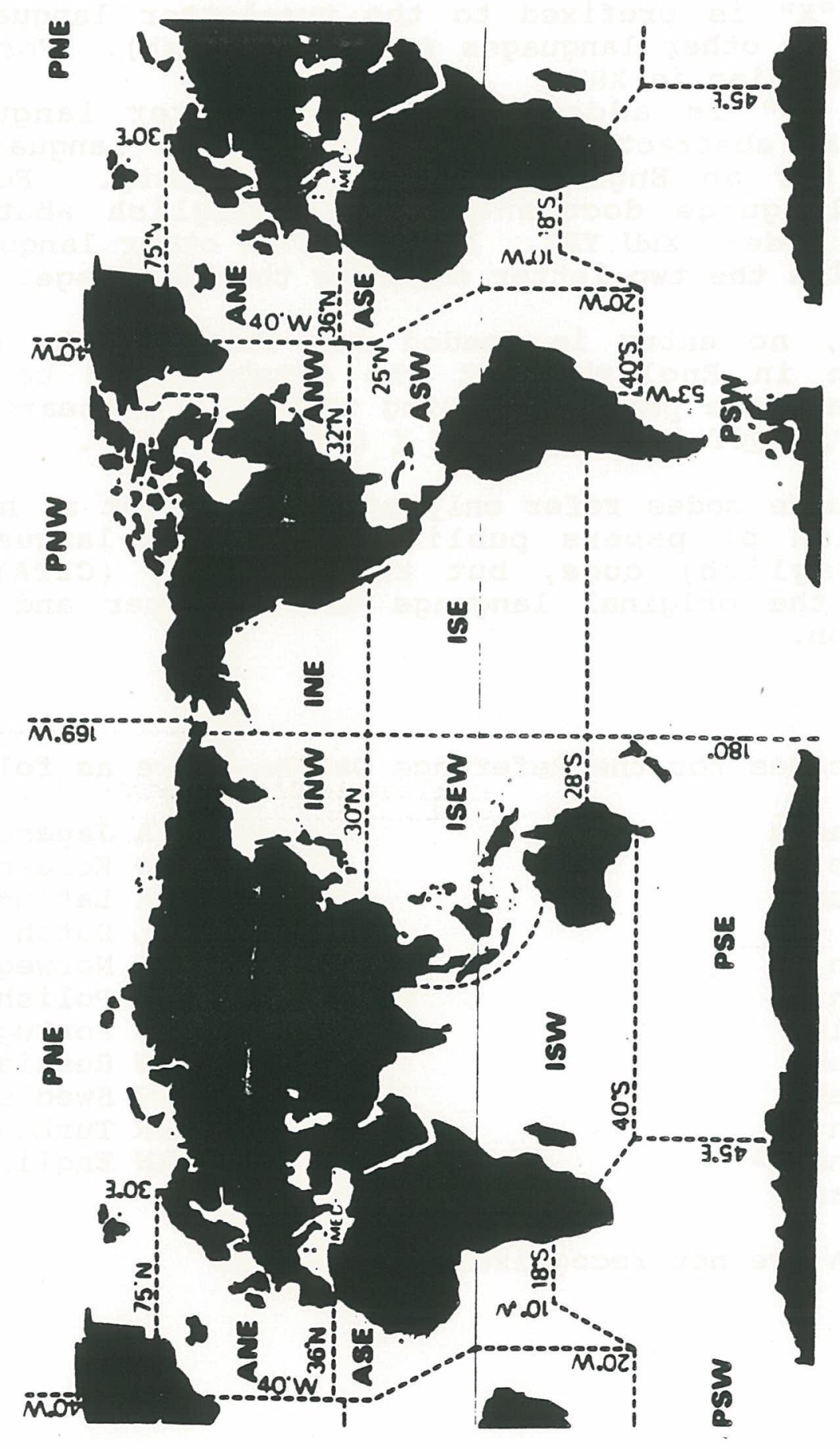




\section{Reference Database -- Page 17}

GEOA -- Geographic Location A (label GA) - The location of the work described in the reference is indexed by geographic codes generally following those of the Aquatic Sciences and Fisheries Information System (ASFIS):

$\begin{array}{ll}\text { ANE } & \text { Northeast Atlantic } \\ \text { ANW } & \text { Northwest Atlantic } \\ \text { ASW } & \text { Southeast Atlantic } \\ \text { Southwest Atlantic } & \\ \text { INE } & \text { Northeast Pacific } \\ \text { INW } & \text { Northwest Pacific } \\ \text { ISE } & \text { Southeast Pacific } \\ \text { ISEW } & \text { Southwest Pacific } \\ \text { ISW } & \text { Indian Ocean } \\ \text { MED } & \text { Mediterranean } \\ \text { PNE } & \text { Eastern Arctic Ocean } \\ \text { PNW } & \text { Western Arctic Ocean } \\ \text { PSE } & \text { Eastern Antarctic Ocean } \\ \text { PSW } & \text { Western Antarctic Ocean } \\ \text { CSL* } & \text { Coastal Waters } \\ \text { FSR* } & \text { Freshwater } \\ \text { COS* } & \text { Cosmopolitan }\end{array}$

The species codes are combined with the ocean area codes. For example, a paper on Megaptera novaeangliae in the Indian ocean is indexed with the codes ISWAC2A (ISW for the Indian Ocean and AC2A for Megaptera novaeangliae).

GEOB -- Geographic Location B (label GB) - The location of the work described in the reference may be further indicated by using the names of the geographic areas. These follow ASFIS Authority Lists for seas, Undersea Features, currents, Inter-territorial Inland Waters, and Inland and coastal areas. For example, a document that appears in the GEOA field with the code PNWAAIA (Western Arctic Ocean, Balaena mysticetus), may also have the name "Beaufort sea" in the GEOB field. Often the ASFIS list gives names that include a large area, so these may be combined with more specific identification of geographic areas. For example, Vancouver Island is not given in the ASFIS Geographic Authority List, so papers concerning Eschrichtius robustus near Vancouver Island could use the location "British Columbia" from ASFIS and a more specific identification of "Vancouver Island". 


\section{Reference Database -- Page 18}

GEOC -- Geographic Location C (label GC) - Latitude and longitude are entered in this (GEOC) field when they are indicated in the document. Latitude and longitude are given in degrees "N" or "S" for latitude, and "E" or "W" for longitude (two digits for latitude degrees and three digits for longitude degrees). The entries are connected directly with species by their codes. The latitude and longitude coordinates provide a means of searching for specific locations or for larger areas by using a range of latitudes or longitudes, separately. To avoid confusion between the coordinates of different locations, latitudes and longitudes should be search separately.

LOCATE -- Location of the documents (label LO) - The physical locations of documents referred to in the Reference Database are indicated by the Location Field (LOCATE), at the end of each record. One or more of the following codes are used for local Woods Hole collections:

PLT - - P. L. Tyack's reprint collection, arranged by author and date.

Shiv -- The bookshelves in Shiverick House at WHOI. For example, Reports of the International Whaling Commission. Often these "Shiverick" documents are a part of the MBL Library collection kept at Shiverick. A subfield gives the MBL Library call number.

WAW -- W.A. Watkins' library, arranged by subject, author, and date. The filing subject is noted in the database (LOCATE) field.

WES - - W. E. Schevill's library, arranged by accession number (the same number as the database record Retrieval Code).

MBL -- Marine Biological Laboratory, the joint Woods Hole library collection supported by MBL, WHOI, and NMFS, and housed at the Lilly Building of the MBL. The MBL Library call number is given in a subfield.

Library of Congress Number is given when appropriate.

The Location Field is indexed so that document searches can be restricted to a particular library or collection. 
Reference Database -- Page 19

The Data Structure for the Reference Database is as follows:

\begin{tabular}{|c|c|c|c|c|}
\hline Field & Field & & & \\
\hline LABEL & NAME & INDEX & SORT & EMPHASIS \\
\hline $\mathrm{RN}$ & RECNO & $\mathrm{T}$ & 2 & 1 \\
\hline CI & CITA & $\mathrm{N}$ & & \\
\hline $\mathrm{AU}$ & AUTHOR & $\mathrm{Y}$ & 5 & 1 \\
\hline YR & YEAR & $\mathrm{Y}$ & 5 & 1 \\
\hline DA & DATE & $\mathrm{N}$ & & \\
\hline TI & TITLE & $\mathrm{N}$ & & \\
\hline so & SOURCE & $\mathrm{N}$ & & \\
\hline VO & VOLUME & $\mathrm{N}$ & & \\
\hline IS & ISSUE & $\mathrm{N}$ & & \\
\hline $\mathrm{PP}$ & PAGES & $\mathrm{N}$ & & \\
\hline ED & EDITOR & $\mathrm{Y}$ & 5 & 1 \\
\hline ET & EDITON & $\mathrm{N}$ & & \\
\hline PC & PUBCO & $\mathrm{N}$ & & \\
\hline $\mathrm{PL}$ & PUBLOC & $\mathrm{N}$ & & \\
\hline $\mathrm{CO}$ & CODEN & $\mathrm{T}$ & 5 & 1 \\
\hline TY & TYPE & $\mathrm{T}$ & 5 & 1 \\
\hline LG & LANGU & $\mathrm{T}$ & 5 & 1 \\
\hline GS & GENSP & $Y$ & 5 & 1 \\
\hline $\mathrm{TX}$ & TAXO & $Y$ & 5 & 1 \\
\hline SM & SUBJMJ & $Y$ & 5 & 1 \\
\hline SJ & SUBJ & $\mathrm{Y}$ & 5 & 1 \\
\hline$P I$ & PICTU & $Y$ & 5 & 1 \\
\hline OD & OBSDATE & $Y$ & 5 & 1 \\
\hline $\mathrm{GA}$ & GEOA & $\mathrm{Y}$ & 5 & 1 \\
\hline GB & GEOB & $Y$ & 5 & 1 \\
\hline GC & GEOC & $Y$ & 5 & 1 \\
\hline $\mathrm{NT}$ & NOTES & $\mathrm{N}$ & & \\
\hline LO & LOCATE & $\mathrm{T}$ & 5 & 1 \\
\hline QU & QUEST & $Y$ & 5 & 1 \\
\hline DF & DEFINE & $\mathrm{N}$ & & \\
\hline
\end{tabular}

See INMAGIC manual for descriptions of categories for indexing, sorting, and emphasis. 


\section{Reference Database -- Page 20 \\ Examples of Database Record Entries --}

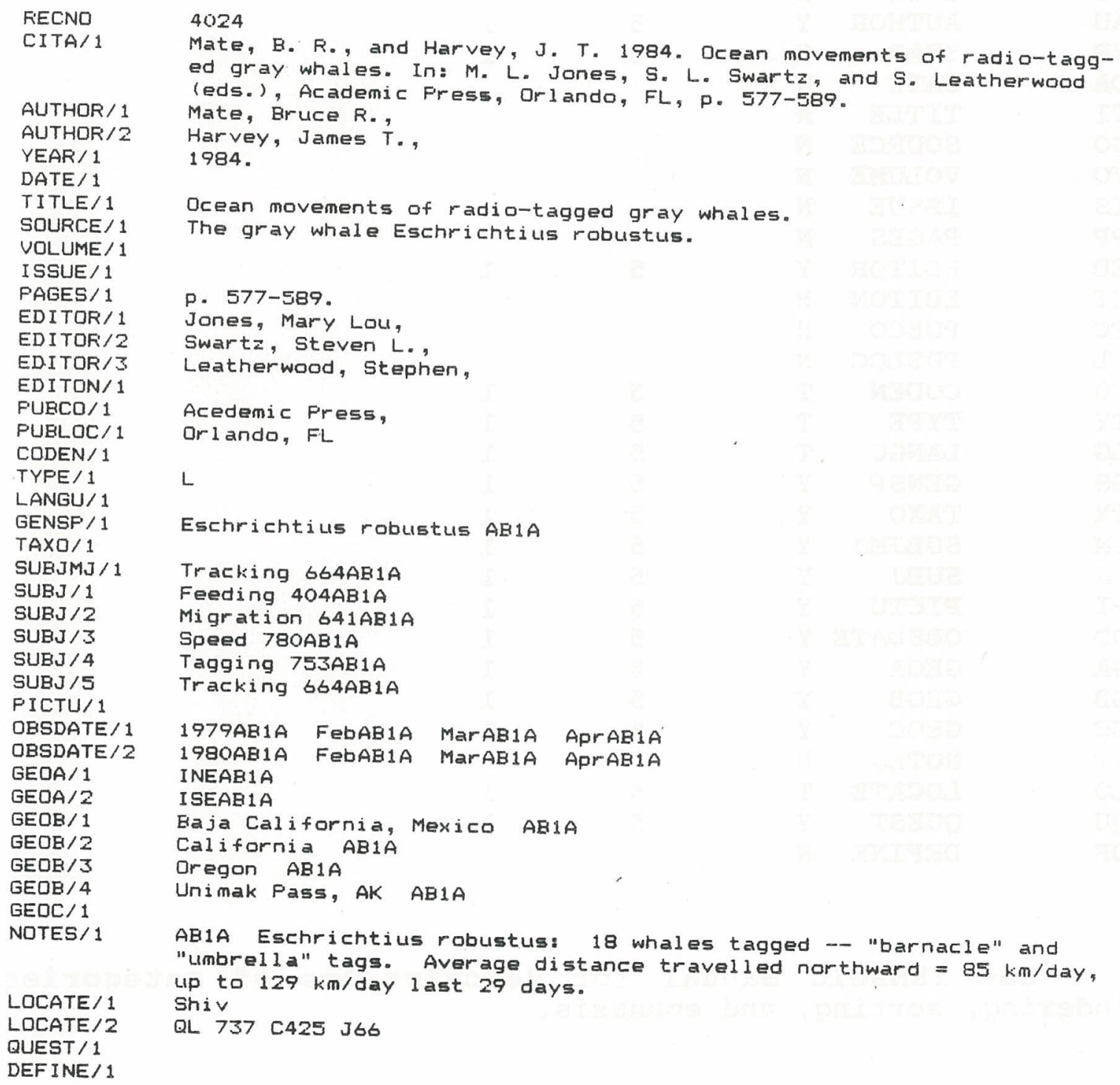




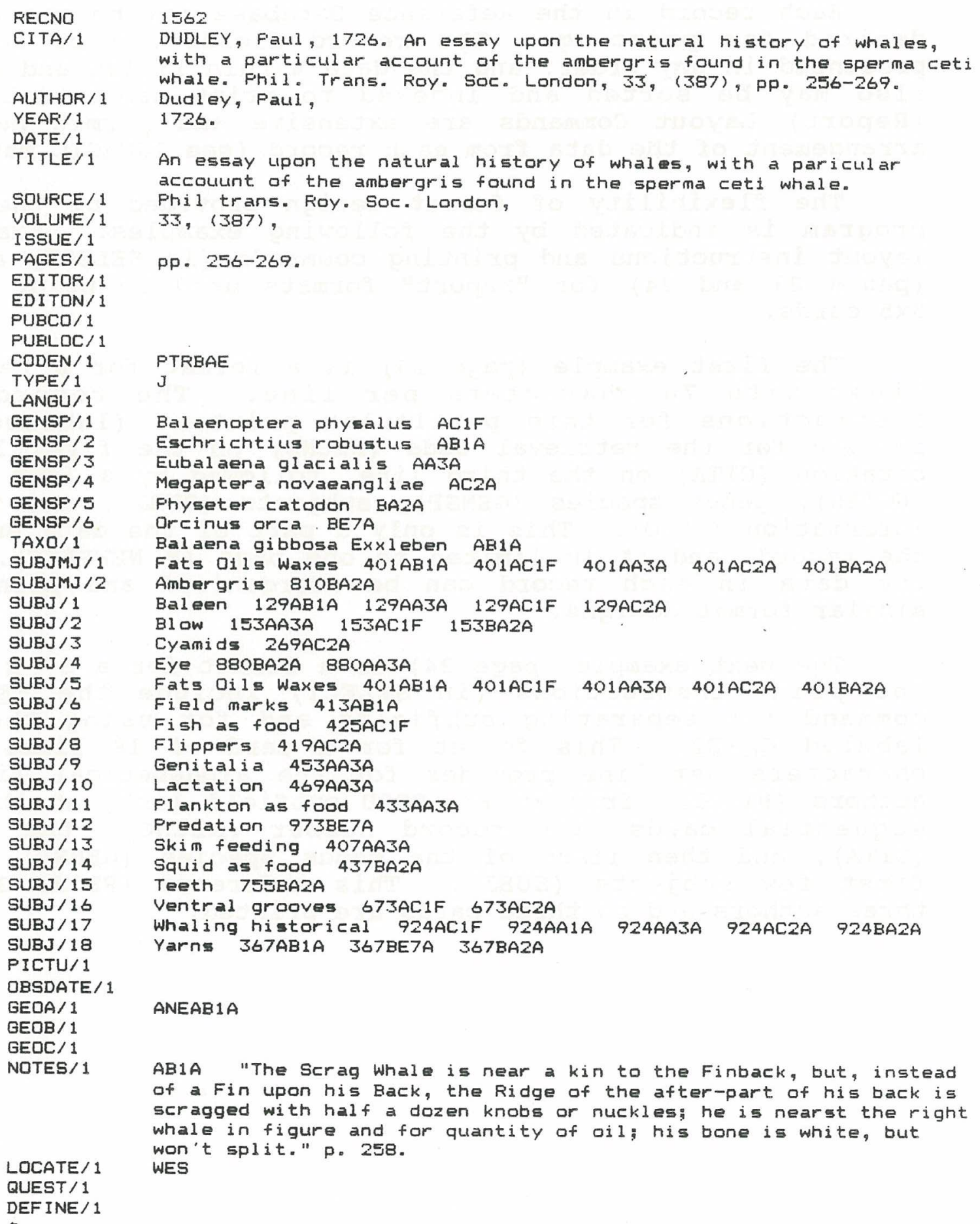


Reference Database -- Page 22

Format of Printed Records --

Each record in the Reference Database may be rearranged as desired for printing. The record fields may be sorted and presented in any order, and the data within fields and subfields also may be sorted and indexed to print sequentially. The (Report) Layout Commands are extensive and permit nearly any arrangement of the data from each record (see INMAGIC manual).

The flexibility of format design provided by the INMAGIC program is indicated by the following examples. Examples of layout instructions and printing commands (in SELECT) are given (pages 23 and 24) for "report" formats used to print pages or $3 \times 5$ cards.

The first example (page 23) is a format for a page of 66 Iines with 70 characters per line. The record layout instructions for this particular printout (labeled PAGEI) provide for the retrieval code (RECNO) on the first line, the citation (CITA) on the third line, followed by a list of notes (NOTES), genus species (GENSP), subjects (SUBJ), and taxonomic information (TAXO). This is only a part of the data entered in the record, and it is limited to one page (@ NEWPAGE). All of the data in each record can be reorganized and printed with similar format designs.

The next example (page 24) is a format for a $3^{\prime \prime} \times 5^{\prime \prime}$ card. The print instructions (in SELECT) include the "EXPLODED" command for separating subfields and for using the format labeled CARD2. This format for a card of 18 lines with 47 characters per line provides for the alphabetical listing of authors (@INDEX, from an EXPLODED subfield list) at the top of sequential cards, the record number (RECNO), the citation (CITA), and then lists of the genus species (GENSP), and the first few subjects (SUBJ). This reference (RECNO 3135) has three authors and so three cards are printed. 


\section{Reference Database -- Page 23}

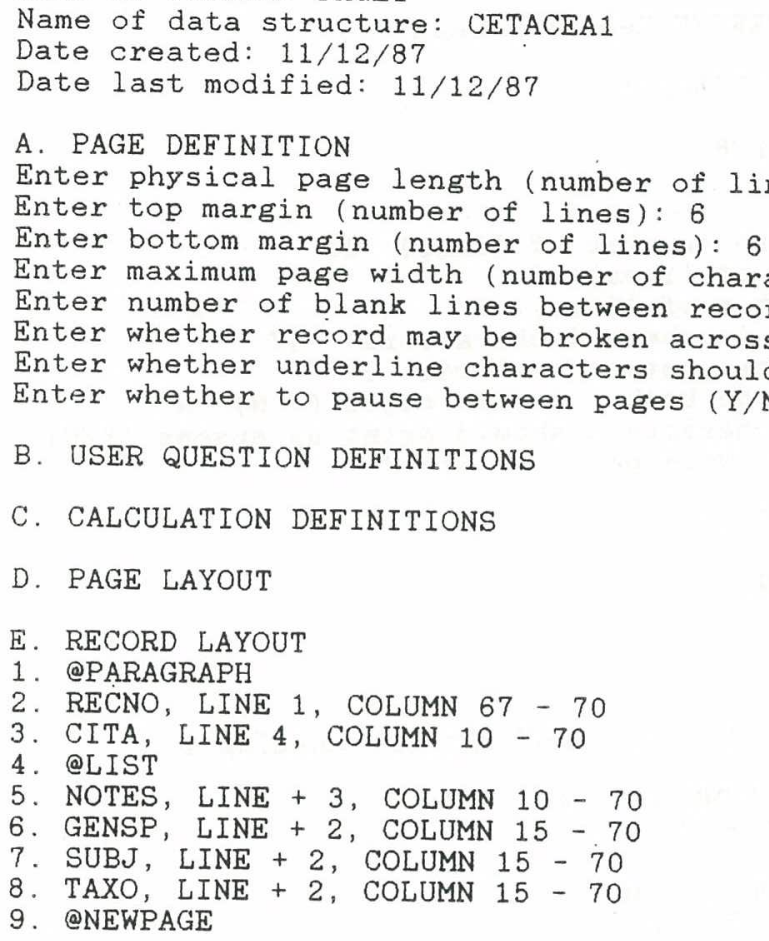

INMAGIC - SELECT

Enter command, or press RETURN for list of commands.

* GET RECNO $=3079$

\#4 number of records: 1

* PRINT \#4 USING PAGE1 MANZER, J. I., 1954. Observations on the gray whale. Jour.
Mamm., 35, (3), pp. 444-445.

AB1A Rhachianectes glaucus: Between $9 / I I /$ and $9 / I V, 1952,31$ whales; evidently none were reported S. of San Diego, \& northernmost one was off Coos Bay, Oregon (43 25N) on $9 / I V$. All whales seen were $\mathrm{N}$-bound, and all between 1.5 and 10.0 miles "from the nearest point of land".






\section{Reference Database -- Page 24}

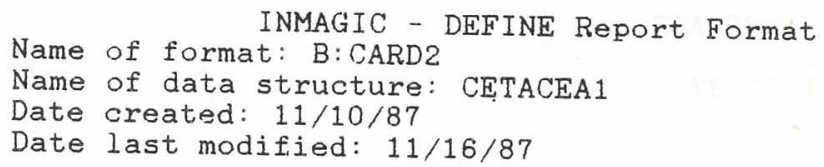

INMAGIC - SELECT

Enter command, or press RETURN for list of commands.

* PRINT \#1 EXPLODED BY AUTHOR USING CARD2

Gentry, R. L.,

KOOYMAN, G. L., NORRIS. K.S., and GENTRY, R.

L., 1975. Spout of the gray whale: its physical characteristics. Science, 190, p. 908-910,

table, fix

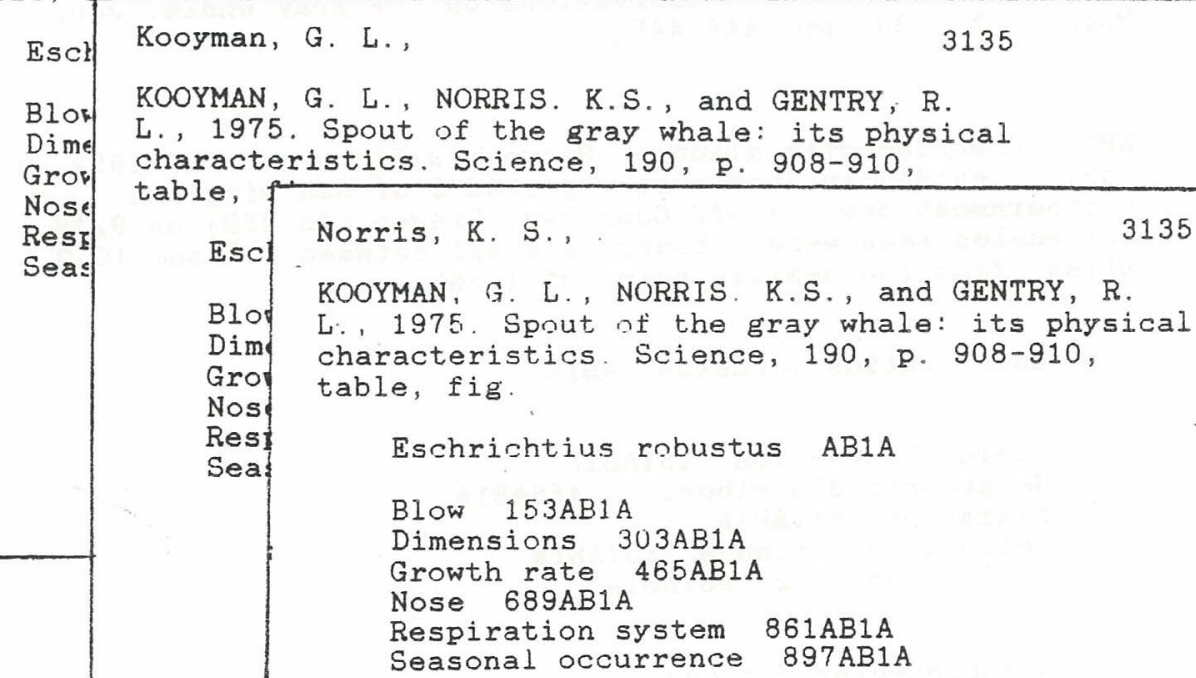


Organization of the Species List --

The list of species for the Reference Database is arranged alphabetically and coded by (1) order/suborder, (2) family, (3) genus, and (4) species. Alphanumeric codes have been assigned to each species referenced in the data base. Initially, these have been assigned in ascending (alphanumeric) order, with spaces for taxonomic revision when needed.

The first place of the species code is a letter representing the order or suborder. The letter "A" denotes the suborder Mysticeti and includes 11 species. The letter "B" denotes the suborder odontoceti and includes 68 species. The letter "C" denotes the order Carnivora, including 37 species of pinnipeds, sea otters, and polar bear. The letter "D" denotes Sirenia and includes 5 species. Other orders and suborders are included in general categories that are also coded by letter $(\mathrm{E}-\mathrm{Z})$.

The second place of the marine mammal species code is a letter representing the family. For example, the species List indicates the Balaenopteridae as code "AC" -- or suborder Mysticeti "A" and family Balaenopteridae "C". The code for Ziphiidae is "BC" -- or suborder odontoceti "B", family Ziphiidae "C".

The third place of the species code is a number of one or two digits representing the genus. For example, the code for Mesoplodon is "BC2" -- or suborder odontoceti "B", family Ziphiidae "C", genus Mesoplodon "3". The code for Kogia is "BA1"-- or suborder Odontoceti "B", family Physeteridae "A", genus Kogia "1". The code for the genus stenella is "BD15" (suborder Odontoceti "B", family Delphinidae "D", and genus stenella "15").

The last place of the species code is a letter representing species. For example, the code for. Kogia breviceps is "BAlA" (suborder Odontoceti "B", family Physeteridae "A", genus Kogia "1", species breviceps "A"). The code for Kogia simus is "BAIB". The code for cephalorhynchus hectori is "BD1D" (suborder Odontoceti "B", family Delphinidae "D", genus Cephalorhynchus "I", species hectori "D"). A reference about finback whales will have "Balaenoptera physalus AC1F" in the genus/species field. 
-

$+$ 


\section{SPECIES LIST}

INMAGIC DATABASE

MARINE MAMMAL LITERATURE 
SPECIES LIST -- 1

Mysticeti -------------- A

Balaenidae ------- AA

Balaena mysticetus Linnaeus 1758 AA1A

Caperea marginata (Gray) $1846 \quad$ AA2A

Eubalaena glacialis (Borowski) 1781 AA3A

Eubalaena australis (Desmoulins) 1822 AA3B

Eschrichtiidae ---- AB

Eschrichtius robustus (Lilljeborg) 1861 AB1A

Balaenopteridae --- AC

Balaenoptera acutorostrata Lacépède $1804 \quad$ AC1A

Balaenoptera borealis Lesson 1828 AC1B

Balaenoptera edeni Anderson 1878 ACIC

Balaenoptera musculus (Linnaeus) 1758 AC1E

Balaenoptera physalus (Linnaeus) 1758 AC1F

Megaptera novaeangliae (Borowski) 1781 AC2A

Odontoceti ------------- B

Physeteridae ------ BA

Kogia breviceps (Blainville) 1838 BAlA

Kogia simus (Owen) 1866

BA1B

Physeter catodon Linnaeus 1758

BA2A

Monodontidae - - - - BB

Delphinapterus leucas (Pallas) 1776 BBIA

Monodon monoceros Linnaeus 1758 BB2A

Ziphiidae -- - - - - BC

Berardius arnuxii Duvernoy $1851 \quad$ BC1A

Berardius bairdii (Stejneger) 1883 BC1B

Hyperoodon ampullatus (Forster) 1770 BC2A

Hyperoodon planifrons Flower 1882 BC2B

Indopacetus pacificus (Longman) 1926 BC3D

Mesoplodon bidens (Sowerby) 1804 BC5A

Mesoplodon bowdoini Andrews 1908 BC5B

Mesoplodon carlhubbsi Moore $1963 \quad$ BC5C

Mesoplodon densirostris (Blainville) 1817 BC5D

Mesoplodon europaeus Gervais 1855 BC5E

Mesoplodon gervaisi (Deslongchamps) 1866 BC5G

Mesoplodon ginkgodens Nishiwaki and Kamiya 1958 BC5H

Mesoplodon grayi von Haast 1876 BC5J

Mesoplodon hectori (Gray) 1871 BC5K

Mesoplodon layardii (Gray) 1865 BC5L

Mesoplodon mirus True 1913 BC5M

Mesoplodon stejnegeri True 1885 BC5S

Tasmacetus shepherdi oliver 1937 BC7A

Ziphius cavirostris G. Cuvier 1823 BC9A 
Delphinidae ----- - BD

Cephalorhynchus commersonii Lacépède $1804 \quad$ BD1A

Cephalorhynchus eutropia (Gray) 1846(9?) BD1B

Cephalorhynchus heavisidii (Gray) 1828 BD1C

Cephalorhynchus hectori van Beneden 1881 BD1D

Delphinus bairdii Dall $1873 \quad$ BD3A

Delphinus delphis Linnaeus 1758 BD3B

Grampus griseus (Cuvier) 1812 BD4A

Lagenorhynchus acutus (Gray) 1828 BD6A

Lagenorhynchus albirostris Gray $1846 \quad$ BD6B

Lagenorhynchus australis (Peale) $1848 \quad$ BD6C

Lagenorhynchus cruciger (Quoy and Gaimard) 1824 BD6E

Lagenorhynchus hosei Fraser 1957 BD6F

Lagenorhynchus obliquidens Gill 1865 BD6G

Lagenorhynchus obscurus (Gray) $1828 \quad$ BD6H

Lissodelphis borealis (Peale) 1848 BD8A

Lissodelphis peronii (Lacépède) 1804 BD8B

Peponocephala electra (Gray) $1846 \quad$ BD10A

Sotalia borneensis Lydekker 1901 BD12A

Sotalia fluviatilis (Gervais) $1855 \quad$ BD12B

Sousa chinensis (Osbeck) 1765 BD13A

Sousa tëuszii (Kukënthal) 1892 BD13C

Stenella attenuata (Gray) 1846 BD15A

Stenella clymene Gray $1850 \quad$ BD15B

Stenella coeruleoalba (Meyen) $1833 \quad$ BD15C

Stenella frontalis (G. Cuvier) 1829 BD15F

Stenella longirostris (Gray) 1828 BD15L

Steno bredanensis (Cuvier) $1828 \quad$ BD17A

Tursiops aduncus (Ehrenberg) 1832 BD19A

Tursiops catalenia (Gray) 1868 BD19B

$\begin{array}{ll}\text { Tursiops gillii Dall } 1873 & \text { BD19C }\end{array}$

Tursiops truncatus (Montagu) 1821 BD19D

Globicephalidae - BE

Feresa attenuata Gray $1874 \quad$ BE1A

Globicephala edwardii Smith $1934 \quad$ BE3A

Globicephala macrorhynchus (Gray) $1846 \quad$ BE3B

Globicephala melaena (Traill) 1809 BE3C

Globicephala scammoni Cope $1869 \quad$ BE3D

Orcaella brevirostris (Owen 1866) BE5A

Orcaella fluminalis Anderson 1871 BE5B

orcinus orca (Linnaeus) 1758 BE7A

Pseudorca crassidens (Owen) $1846 \quad$ BE9A

Phocoenidae - - - BF

Australophocaena dioptrica Lahille 1912 BF1A

Phocoena phocoena (Linnaeus) 1758 BF2A

Phocoena spinipinnis Burmeister $1865 \quad$ BF2B

Phocoena sinus Norris and McFarland $1958 \quad$ BF2C

Phocoenoides dalli (True) 1885 BF4A

Neophocaena phocaenoides (G.Cuvier) 1829 BF6A 


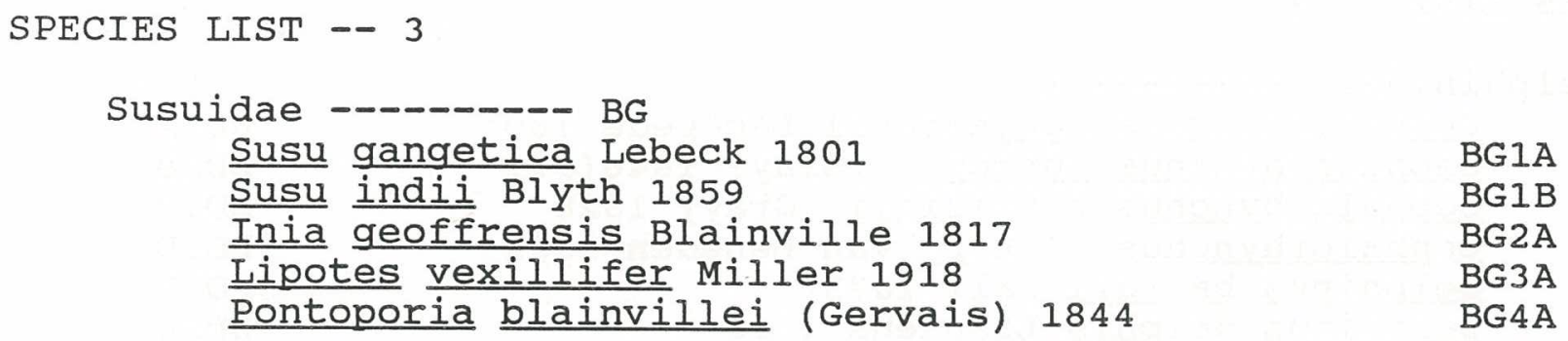




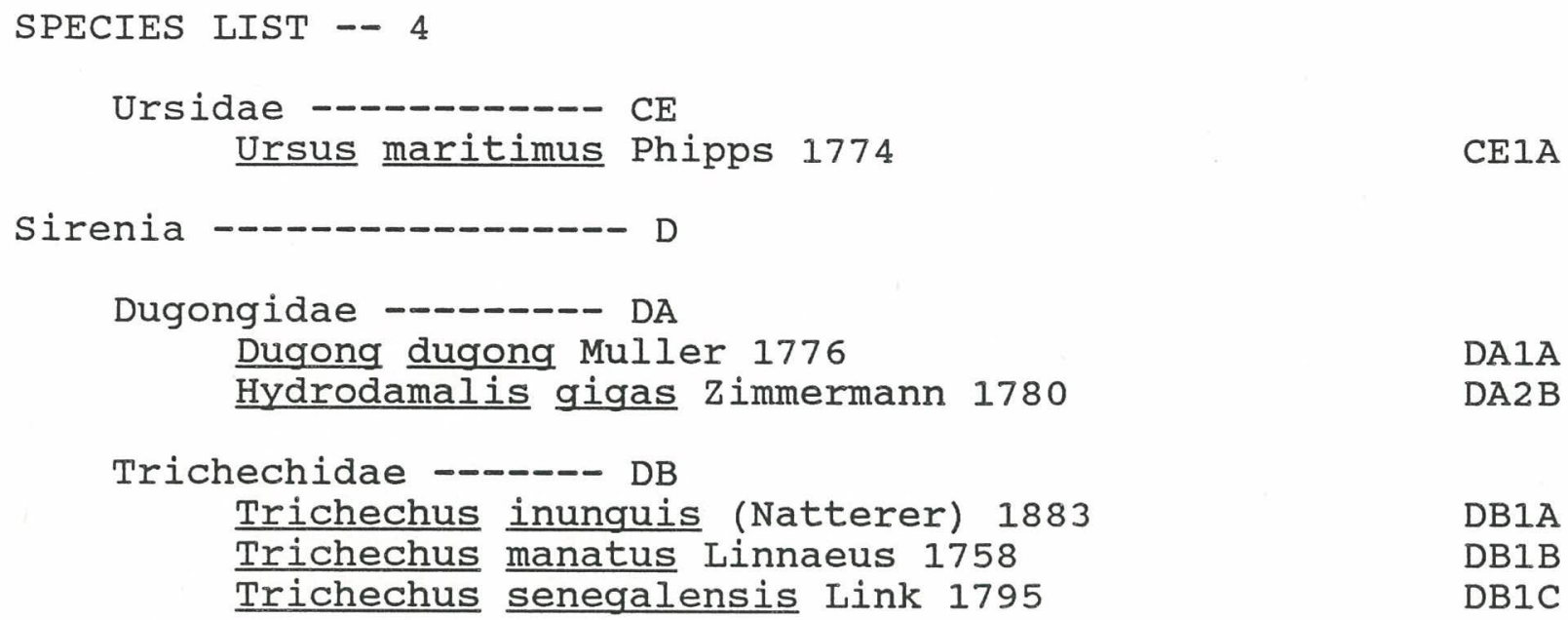


$\frac{0}{0}$

$\rightarrow$

E

0

D

co

so

D

2

a

ac

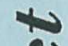

(2)

0

2 
SUBJECT HEADINGS

INMAGIC DATABASE

MARINE MAMMAL LITERATURE REFERENCES 
Subject Headings (underlined and numbered)

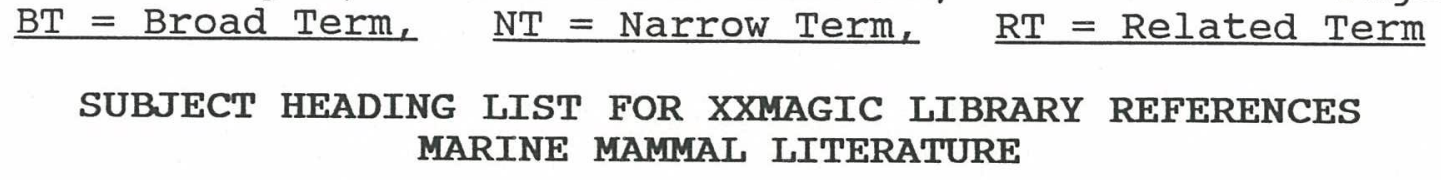

Woods Hole Oceanographic Institution

Non-underlined subjects are for reference only. (Species are listed separately and are coupled directly with each subject in references.)

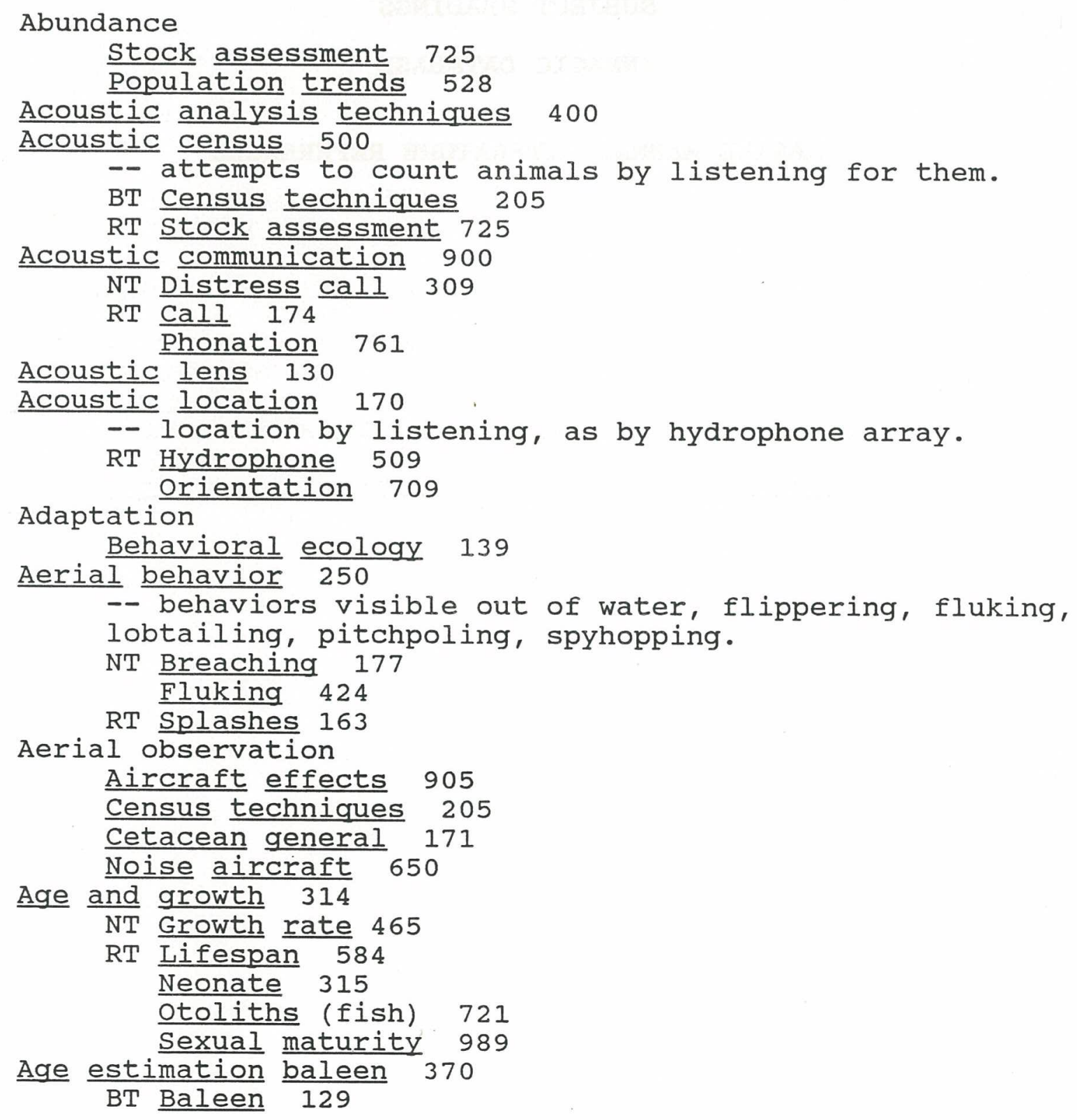


Subject Headings (underlined and numbered) $\underline{\mathrm{BT}}=$ Broad Term, $\underline{\mathrm{NT}}=$ Narrow Term, $\underline{\mathrm{RT}}=$ Related Term

Age estimation bone 390

BT Osteology 717

Age estimation corpora lutea 410

BT Reproductive system 849

Age estimation ear plug 450

BT Ear 113

Age estimation tag returns 490

BT Mark recapture 609

Tagging 753

Age estimation teeth 530

BT Teeth 755

RT Growth rate 465

Aggression

Agonistic behavior 570

Agonistic behavior 570

Aircraft

Aircraft effects 905

Noise aircraft 650

Aircraft effects 905

-- effect of aircraft presence, shadow, noise on animals.

RT Noise aircraft 650

Noise effects industrial 537

Albinism 730

Ship effects 300

RT Pigmentation 233

Allomaternal 760

RT Care giving 201

Parental 617

Allometry 750

Altruism 770

Ambergris 810

RT Digestive system 301

Ambient noise 850

NT Noise aircraft 650

Geologic noise 335

Noise industrial 533

Noise seismic exploration 909

Noise ship 277

Splashes 163

RT Rain 821

Amplifier 890

-- discussion of amplifiers, not the mention of those used.

RT Hydrophone 509

$$
\text { Recording system } 829
$$

Anatomical subjects

Anatomy (general) 325

Baleen 129

Blowhole 157

Digestive system 301

Ear 113

Endocrine system 361

Eye 880 
Subject Headings (underlined and numbered)

$\mathrm{BT}=$ Broad Term $\quad \mathrm{NT}=$ Narrow Term, Page 3

Anatomical subjects (continued)

Fin (and dorsal carina) 337

Flippers 419

Flukes 421

Genitalia 453

Heart 489

Hormones 497

Kidney 565

Larynx 577

Lung 317

Meat 625

-- commercial consumption.

Melon 629

Mouth 660

-- includes tongue, rorqual adaptations.

Muscles 669

Nervous system 681

Nose 689

-- includes anatomy, nasal passages.

Osteology 717

Pelvis 319

Reproductive system 849

-- includes ovaries, testes.

Respiratory system 861

Skull 257

Tail 900

-- "peduncle", small.

Teeth 755

Throat 249

Vascular system 223

Ventral grooves 673

Vestigial organs 210

Viscera 215

Anatomy (general) 325

-- see anatomical subjects.

Anecdote

Yarn 367

Anesthesia 930

Apnoea

Respiration rate 857

Aquarium

Captivity 193

Array

Acoustic location 170

Hydrophone 509

Asymmetry 101

Attacking

-- bilateral anatomical asymmetry.

Agonistic behavior 570

Attendance Behavior

Allomaternal 760

Parental 617 





Subject Headings (underlined and numbered) $\underline{\mathrm{BT}}=$ Broad Term, $\quad \underline{\mathrm{NT}}=$ Narrow Term,

Behavior 312 (continued)

NT Object interaction 693

Parental 617

Predator defense 801

Resting behavior 863

Schooling 889

Sexual behavior 929

Sleep 927

Social behavior 957

Social play 958

Wave riding 160

Behavioral ecology 139

-- behavioral adaptations to environment.

Benthos as food 423

Bibliography

-- a separate code in the document TYPE field.

Biochemistry 141

Biogeography 143

Bioluminescence 145

Bird marine mammal 605

-- interactions between birds and marine mammals.

BT Mixed species 645

Birth 745

RT Gestation 457

Juvenile 557

Neonate 515

Parental 617

Blindness 149

BT Pathology 749

Blood 917

RT Heart 489

Blow 153 - visibility, audibility, and physical characteristics.

NT Underwater blow 817

BT Respiratory system 861

RT Blowhole 157

Respiration rate 857

Blowhole 157

BT Respiratory system 861

RT Blow 153

Respiration rate 857

Blubber 161

-- thickness, composition, function.

RT Fats oils waxes 401 Skin 373

Boat traffic

Noise ship 277

Ship effects 300

Body shape

Dimensions 305

Hydrodynamic 505 
Subject Headings (underlined and numbered)

$\underline{\mathrm{BT}}=$ Broad Term,$\quad \underline{\mathrm{NT}}=$ Narrow Term, $\quad \underline{\mathrm{RT}}=$ Related Term

Body temperature 159

RT Thermoregulation 583

Bone

Age estimation bone 390

Osteology 717

Bonnet $\begin{array}{ll}\text { Skull } & 257\end{array}$

Callosities 165

Dermal hardening 285

Book reviews

Literature review 593

Review 169

Bow riding

Locomotion 597

Wave riding 160

Brain 173

BT Nervous system 681

RT Intelligence 545

Learning 582

Breaching 177

Memory 633

BT Aerial behavior 250

RT Fluking 424

Splashes 163

Bubble feeding 181

-- bubbles observed during feeding.

BT Feeding 404

Calf

RT Food 422

Allomaternal 760

Birth 745

Juvenile 557

Neonate 315

Parental 617

Call 174

BT Phonation 761

Callosities 165

RT Dermal hardening 285

Individual identification 529

Skin 373

Captive release 677

-- release or recovery of captives.

RT Captivity 193

Captivity 193

RT Entrapment 371

Incidental catch 525

Capture techniques 197

RT Captive release 677

Care giving 201

Catch statistics

Whaling statistics 167 
Subject Headings (underlined and numbered)

Page 7

$\underline{\mathrm{BT}}=$ Broad Term, $\underline{\mathrm{NT}=\text { Narrow Term, }} \underline{\mathrm{RT}=\text { Related Term }}$

Cavitation

Census

Hydrodynamic sound 507

Acoustic census 205

Census techniques 500

Stock assessment 725

Census techniques 205

NT Acoustic census 5

RT Stock assessment 725

Cetacean general 171

-- general information.

RT Pinniped general 118

Chemical communication 209

Chemistry -- see communication.

Biochemistry 141

Blood 917

Chemical communication 209

Chemoreception 213

Contaminants 245

Chemoreception 213

RT Olfaction 705

Circuit $\frac{\text { Tast }}{217}$

-- schematics, detailed descriptions, not listing of equipment in use.

Circulatory system

Click 221

Vascular system 223

BT Phonation 761

RT Acoustic communication 900

Cochlea

$$
\text { Echolocation } 345
$$

\section{Ear 113}

Coda 225

NT Signature signal 953

BT Phonation 761

RT Acoustic communication 900

Cognition 229

Individual identification 529

Collector's troubles 397

Color RT Yarns 367

Albinism 730

Pigmentation 233

Communication

Acoustic communication 900

Chemical communication 209

Olfaction 705

Touch 800

Visual Communication 


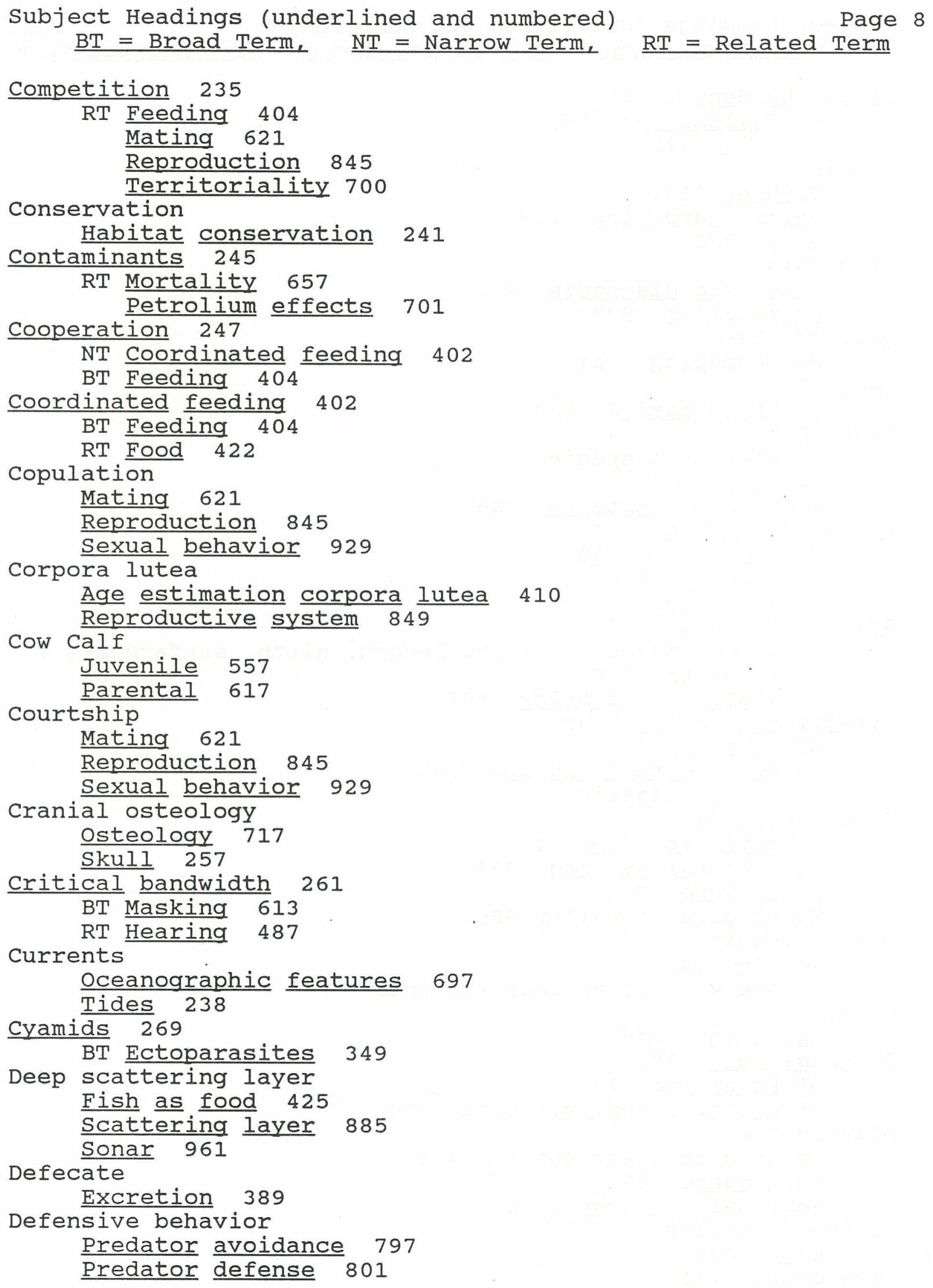


Subject Headings (underlined and numbered) $\underline{\mathrm{BT}}=$ Broad Term, $\underline{\mathrm{NT}}=$ Narrow Term, $\underline{\mathrm{RT}}=$ Related Term

Dermal hardening 285

RT Callosities 165

Dermis Skin 373

Blubber 161

Dermal hardening 285

Skin 373

Diagnosis

Taxonomic diagnosis 287

Systematics 978

Dialect 289

BT Phonation 761

Diel 293

RT Photo period 273

Diet 295

-- diet of a species.

BT Food 422

RT Stomach contents 486

Digestive system 301

RT Ambergris 810

Feeding 404

Food 422

Dimensions 305

-- measurements including length, girth, surface area.

RT Allometry 750 Whaling statistics 167

Directional hearing 993

BT Hearing 487

RT Sound directionality 985

Directionality -- propagation.

Acoustic location 170

Directional hearing 993

Hydrophone 509

Sound directionality 985

Discrimination

Hearing 487

Disease

-- see visual, various subjects

Pathology 749

Distress call 309

BT Phonation 761

RT Acoustic communication 900

Distribution

Geographic distribution 455

Home range 493

Seasonal occurrence 897

Diurnal behavior

Diel 293

Dive depth 281

BT Diving 321

RT Diving physiology 325 
Subject Headings (underlined and numbered)

Page 10

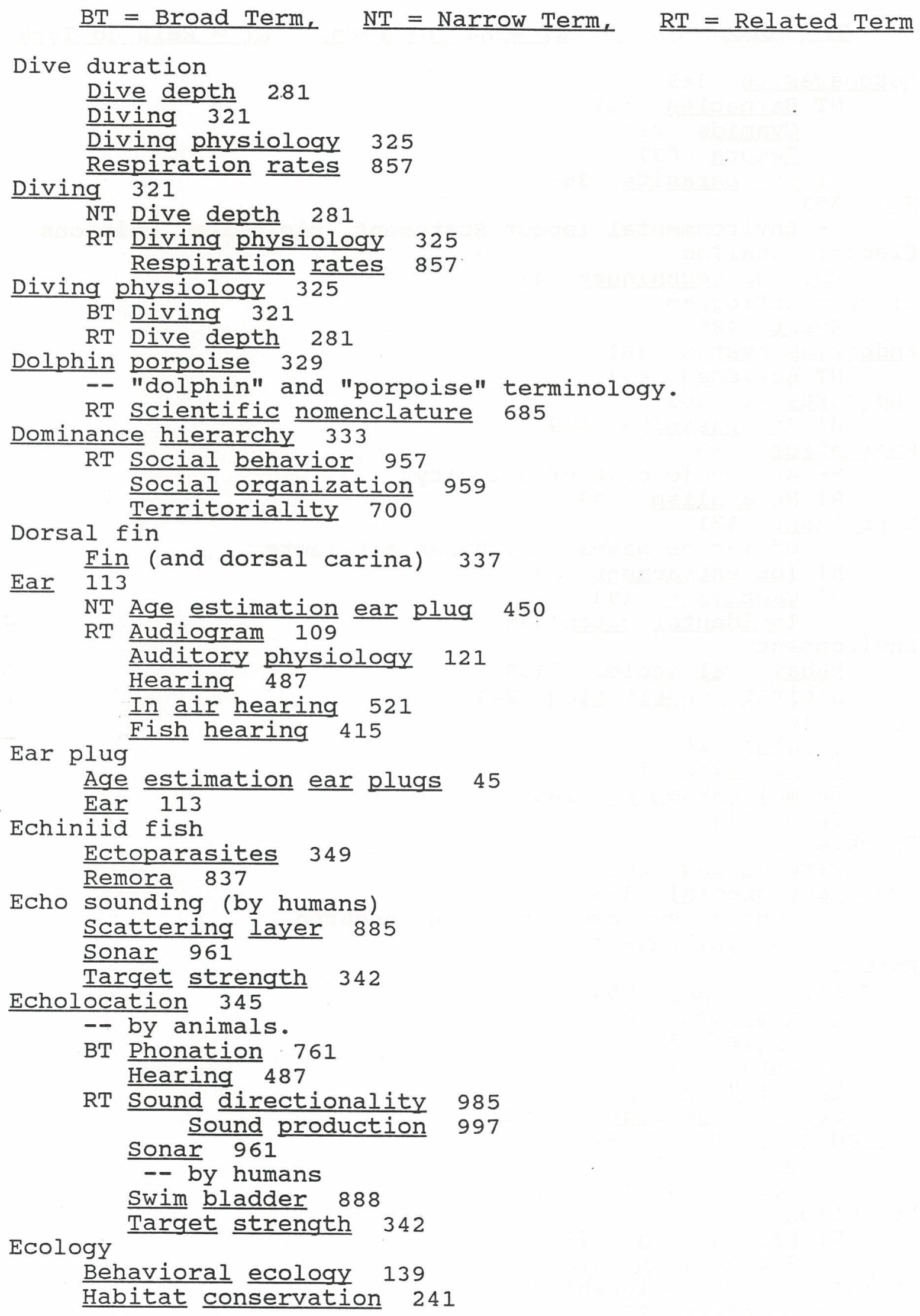


Subject Headings (underlined and numbered)

$$
\underline{\mathrm{BT}}=\text { Broad Term, } \underline{\mathrm{NT}=\text { Narrow Term, }} \underline{\mathrm{RT}}=\text { Related } \text { Term }
$$

Ectoparasite 349

NT Barnacles 137

Cyamids 269

Remora 837

EIS 353

RT Endoparasite 365

Electric whaling

Whaling techniques 432

Electrocardiogram

Heart 489

Endocrine system 361

NT Hormones 498

Endoparasite 365

RT Ectoparasite 349

Energetics 369

-- energetic cost of activity.

RT Metabolism 637

Entrapment 371

-- of marine mammals by human artifacts.

NT Ice entrapment 877

RT Captivity 193

$$
\text { Incidental catch } 525
$$

Environment

Behavioral ecology 139

Habitat conservation 241

Epidermis

Blubber 161

Callosities 165

Dermal hardening 285

Skin 373

Epimeletic

Care giving 201

Equipment special 375

-- unusual equipment used in research.

-- see Instruments.

Escort

Allomaternal 760

Care giving 201

Juvenile 557

Parental 617

Social behavior 957

Social organization 951

Evoked potentials 381

RT Brain 173

Nervous system 681

Evolution 385

RT Paleontology 733

Systematics 978

Evolutionary Relationships

Systematics 978 
Subject Headings (underlined and numbered)

$\underline{\mathrm{BT}}=$ Broad Term, $\underline{\mathrm{NT}=\text { Narrow Term }, \quad \underline{\mathrm{RT}}=\text { Related Term }}$

Excrescences

Callosities 165

Dermal hardening 285

Excretion 389

Explosives

Noise seismic exploration 909

Whaling techniques 432

Extinction 393

Eye 880

-- see vision, various subjects.

RT In air vision 523

Underwater vision 445

Visual physiology 825

Fats oils waxes 401

-- from marine mammals, not petroleum.

NT Spermaceti 464

RT Blubber 161

Feces

Melon 629

Excretion 389

Feeding 404

NT Bubble feeding 181

Coordinated feeding 402

Lunge feeding 406

Skim feeding 407

Suction feeding 408

RT Competition 235

Digestive system 301

Food 422

Schooling 889

Stomach contents 486

Field identification guide 409

Field marks 413

RT Individual identification 529

Pigmentation 233

Field observations 451

-- general notes and observations.

RT Field identification guide 409

Individual identification 529

Fin (and dorsal carina) 337

RT Flippers 419

Fish aging Flukes 421

otholiths 721

Fish as food 425

-- as for marine mammals.

BT Food 422

RT Scattering layer 885

squid as food 437 
Subject Headings (underlined and numbered)

$\underline{\mathrm{BT}}=$ Broad Term, $\underline{\mathrm{NT}}=$ Narrow Term, $\quad \underline{\mathrm{RT}}=$ Related Term

Fish hearing 415

-- audiograms, mechanisms of hearing in fish.

BT Audiogram 109

Hearing 487

RT Auditory physiology 121

Ear 113

Lateral line 581

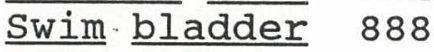

Fish sounds 417

RT Fish hearing 415 Swim bladder 888

Flippering

Aerial behavior 250

Flippers 419

Flippers 419

RT Fin (and dorsal carina) 337

Flukes 421

Flukes (and flippers) 421

RT Fin (and dorsal carina) 337

Flippers 419

Locomotion 597

Fluking 424

$\frac{\mathrm{Tail}}{424} 869$

BT Aerial behavior 250

RT Flukes 421

Splashes 163

Focus

Acoustic lens 130

Eye 880

Visual, various subjects

Foetus 405

NT Multiplets 661

RT Age and growth 314

Growth rate 465

Neonate 315

Food 422

Sex ratio 921

-- for animals.

NT Benthos as food 423

Fish as food 425

Mammals as food 429

Plankton as food 433

Squid as food 437

RT Diet 295

Digestive system 301

Feeding 404

- various subjects.

Metabolism 637

Scattering layer 885

Schooling 889

Stomach contents 486 
Subject Headings (underlined and numbered)

$\underline{\mathrm{BT}}=$ Broad Term, $\underline{\mathrm{NT}}=$ Narrow Term, $\underline{\mathrm{RT}}=$ Related Term

Fossils

Evolution 385

Paleontology 733

Frequency discrimination

Hearing 487

Friendly Whale

Human marine mammal interaction 881

Fur

Hair 471

Molt 257

Skin 373

GARR

Mark recapture 609

Mortality 657

Population models 785

Recruitment 449

Stock assessment 725

General observations

Cetacean general 171

-- general information.

Field observations 451

- general observations.

Geographic distribution 455

-- sightings, occurrence.

Pinniped general 118

-- general information.

Genetics 452

RT Karyotype 883

Sex determination 925

Sex Ratio 921

Genitalia 453

BT Reproductive system 849

RT Field marks 413

Individual identification 529

Mating 621

Sex ratio 921

Sexual behavior 929

Sexual maturity 989

Geographic distribution 455

-- sightings and occurrence records, distribution.

RT Field observations 451

- general.

Home range 493

Population trends 528

Seasonal occurrence 897

Stock assessment 725

Territoriality 700

Geographic range

Geographic distribution 455

Home range 493

Territoriality 700 
Subject Headings (underlined and numbered)

$$
\underline{\mathrm{BT}}=\text { Broad Term, } \underline{\mathrm{NT}}=\text { Narrow Term, } \quad \underline{\mathrm{RT}}=\text { Related Term }
$$

Geologic noise 335

BT Ambient noise 850

RT Noise seismic exploration 909

Gestation 457

NT Foetus 405

BT Reproduction 845

RT Birth 745

Juvenile 557

Mating 621

Neonate 315

Parental 617

Reproductive interval 189

Grooming 461

Growth

$$
\text { -- pinniped. }
$$

Age and growth 314

Growth rate 465

Growth rate 465

NT Age estimation baleen 370

Age estimation bone 390

Age estimation corpora lutea 410

Age estimation ear plug 450

Age estimation tag returns 490

Age estimation teeth 530

BT Age and growth 314

RT Allometry 750

Dimensions 305

Fetus 405

Juvenile 557

Neonate 315

Guide

Sexual maturity 989

Habitat conservation 241

RT Geographic distribution 455

Home range 493

Seasonal occurrence 897

Hair 471

Territoriality 700

RT Molt 254

Vibrissae 631

Harmonic 473

RT Acoustic analysis techniques 400 Phonation 761

Harpoon 477

RT Sealing 893

Whaling techniques 432

Haul-out 481

-- pinniped.

Healing 485

BT Pathology 749

RT Pigmentation 233 
Subject Headings (underlined and numbered)

$\underline{\mathrm{BT}}=$ Broad Term,$\quad \underline{\mathrm{NT}}=$ Narrow Term, $\underline{\mathrm{RT}}=$ Related Term

Health care

Captivity 193

Healing 485

Pathology 749

Hearing 487

-- underwater hearing.

NT Critical bandwidth 261

Directional hearing 993

Fish hearing 415

In air hearing 521

RT Audiogram 109

Auditory physiology 121

Ear 113

Masking 613

Heart 489

RT Blood 917

Vascular system 223

Hematology

Blood 917

Historical

Population trends 528

Whaling historical/logbooks 924

Home range 493

RT Geographic distribution 455

Seasonal occurrence 897

Territoriality 700

Tracking 664

Hormones 497

BT Endocrine system 361

Human marine mammal interaction 881

-- approach by marine mammals.

Hunting

BT Mixed species 645

Predation 793

-- by animals.

Sealing 893

-- by humans.

Whaling 938

Hybrid 501

Hydrodynamic 505

-- effects of water motion.

NT Hydrodynamic sound 507

RT Locomotion 597

Skin 373

Wave riding 160

Hydrodynamic sound 507

-- sounds produced by water movement, not air.

BT Hydrodynamic 505

Hydrophone 509

RT Acoustic location 170

Sonobuoy 973 
Subject Headings (underlined and numbered)

$\underline{\mathrm{BT}}=$ Broad Term,$\quad \underline{\mathrm{NT}}=$ Narrow Term,$\quad \underline{\mathrm{RT}}=$ Related Term

Ice 513

-- influence on animals, sounds.

RT Ice entrapment 877

Ice entrapment 877

BT Entrapment 371

Imitation 517

RT Learning 582

Vocal learning 548

Impact statements

EIS 353

In air hearing 521

-- hearing of air-bourne sounds.

RT Hearing 487

-- underwater.

Audiogram 109

In air sounds 522

-- air-bourne sounds.

RT Blow 153

Call 174

In air vision 523

-- see visual, various subjects.

RT Eye 880

Underwater vision 445

Visual communication 237

Incidental catch 525

NT Tuna marine mammal 357

RT Captivity 193

Capture techniques 197

Entrapment 371

-- by human artifacts.

Ice entrapment 877

Individual identification 529

-- Identification of individual animals by humans through

recognition of color patterns, scars, shapes, sounds.

BT Tagging 753

RT Callosities 165

Field identification guide 409

Field marks 413

Field observations 451

Individual recognition 531

Pigmentation 233

Satellite 873

Signature signal 953

Telemetry 828

Individual recognition 531

-- identification of individuals by other animals.

RT Individual identification 529

-- by humans.

Signature signal 953 


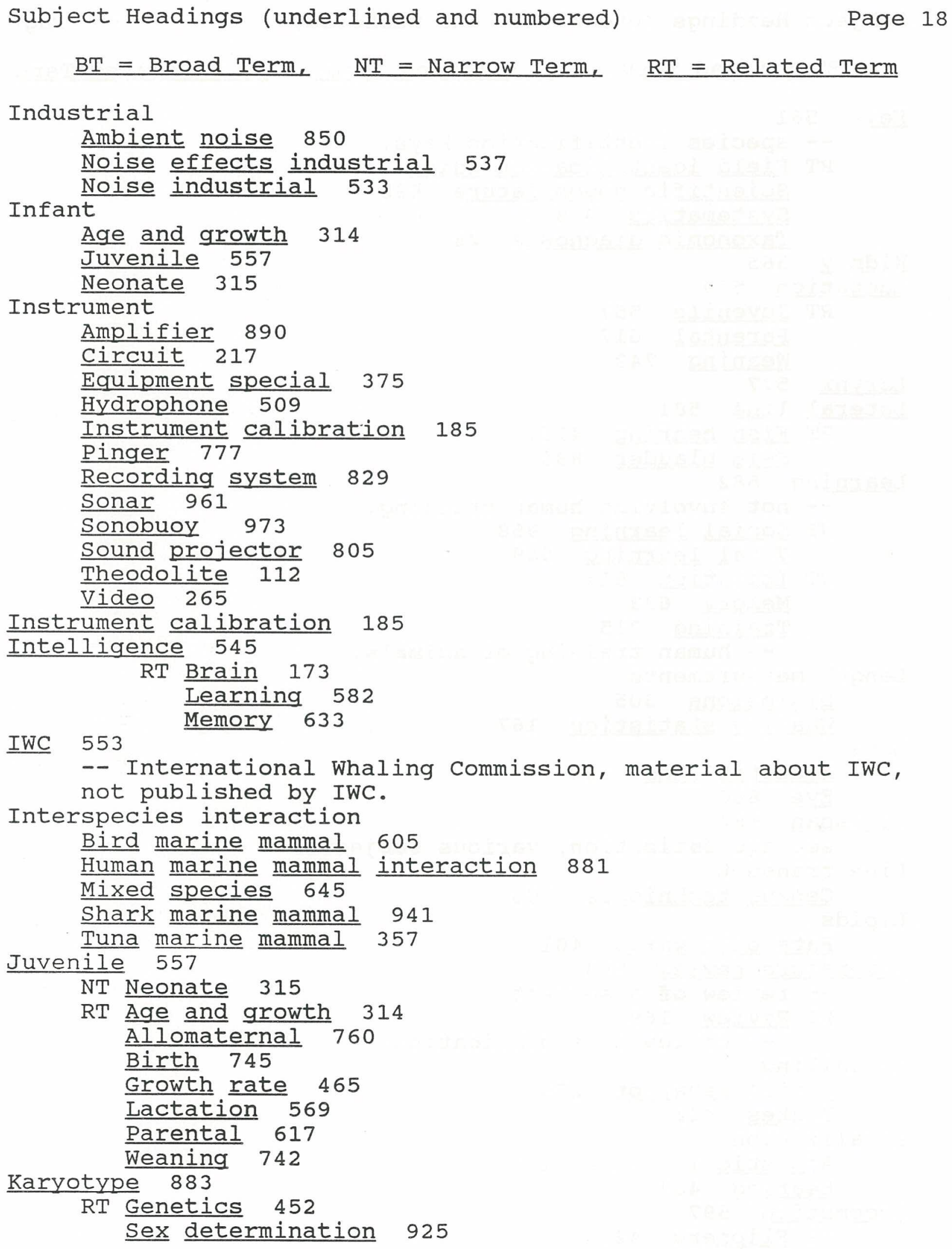


Subject Headings (underlined and numbered)

$\underline{\mathrm{BT}}=$ Broad Term, $\underline{\mathrm{NT}}=$ Narrow Term, $\underline{\mathrm{RT}}=$ Related Term

Keys 561

-- species identification keys.

RT Field identification guide 409

Scientific nomenclature 685

Systematics 978

Kidney 565

Taxonomic diagnosis 287

Lactation 5.69

RT Juvenile 557

Parental 617

Larynx

Weaning 742

Lateral line 581

RT Fish hearing 415

Swim bladder 888

Learning 582

-- not involving human training.

NT Social learning 958

Vocal learning 548

RT Imitation 517

Memory 633

Training 915

-- human training of animals.

Length measurements

Dimensions 305

Whaling statistics 167

Lens

Acoustic lens 130

Eye 880

Lifespan 884

see age estimation, various subjects.

Line transect

Lipids

Census techniques 205

Fats oils waxes 401

Literature review 593

-- review of a subject.

RT Review 169

Lobtailing

-- review of a publication.

Aerial behavior 250

Flukes 421

Localization

Acoustic location 170

Hearing 487

Locomotion 597

RT Flippers 421

Flukes 419

Hydrodynamic 505

Speed 780

Tail 869

Wave riding 160 
Subject Headings (underlined and numbered)

$\underline{\mathrm{BT}}=$ Broad Term,$\quad \underline{\mathrm{NT}}=$ Narrow Term, $\quad \underline{\mathrm{RT}}=$ Related Term

Lunge feeding 406

BT Feeding 404

RT Fish as food 425

Lungs 317

$$
\text { Food } 422
$$

BT Respiratory system 861

RT Blow 153

Magnetic 602

-- sensitivity to magnetic fields.

RT orientation 709

Mammals as food 429

-- for marine animals.

BT Food 422

RT Feeding 404 Predation 793

Mammary Glands

Lactation 569

Neonate 315

Weaning 742

Management

Stock management 955

Mark recapture 609

NT Age estimation tag returns 490

RT Population models 785

Recruitment 449

Stock assessment 725

Tagging 753

Masking 613

NT Critical bandwidth 261

RT Ambient noise 850

Hearing 487

Noise effects industrial 537

Mating 621

See noise, various subjects.

BT Reproduction 845

Sexual behavior 929

RT Competition 235

Genitalia 453

Reproductive system 849

Meat 625

Sexual maturity 989

Melon 629

RT Fats oils waxes 401

Sound directionality 985

Sound production 444

Spermaceti 464 
Subject Headings (underlined and numbered)

$$
\underline{\mathrm{BT}}=\text { Broad Term, } \underline{\mathrm{NT}}=\text { Narrow Term, } \underline{\mathrm{RT}}=\text { Related Term }
$$

Memory 633

-- psychophysical tests of memory.

RT Brain 173

Imitation 517

Individual recognition 531

Intelligence 545

Learning 582 .

Vocal learning 548

Metabolism 637

RT Energetics 369

Food 422

Migration 641

Respiration rates 857

Milk

Lactation 569

Mimicry

Weaning 742

Imitation 517

Mixed species 645

-- aggregations or interactions of more than one species.

NT Bird marine mammal 605

Human marine mammal interaction 881

Shark marine mammal 941

Molt 254

Tuna marine mammal 357

RT $\underline{\text { Hair }} 471$

Skin 373

Mortality 657

NT Stranding dead 931

RT Contaminants 245

Entrapment 371

Ice entrapment 877

Incidental catch 525

Pathology 749

Population models 785

Recruitment 449

Stranding dead 931

Mouth 660

Stranding live 665

-- includes tongue, rorqual adaptations.

RT Baleen 129

Nose 689

Teeth 755

Throat 249

Multiplets 661

RT Birth 745

Foetus 405

Gestation 457

Neonate 315

Muscles 669

RT Energetics 369

Metabolism 637 


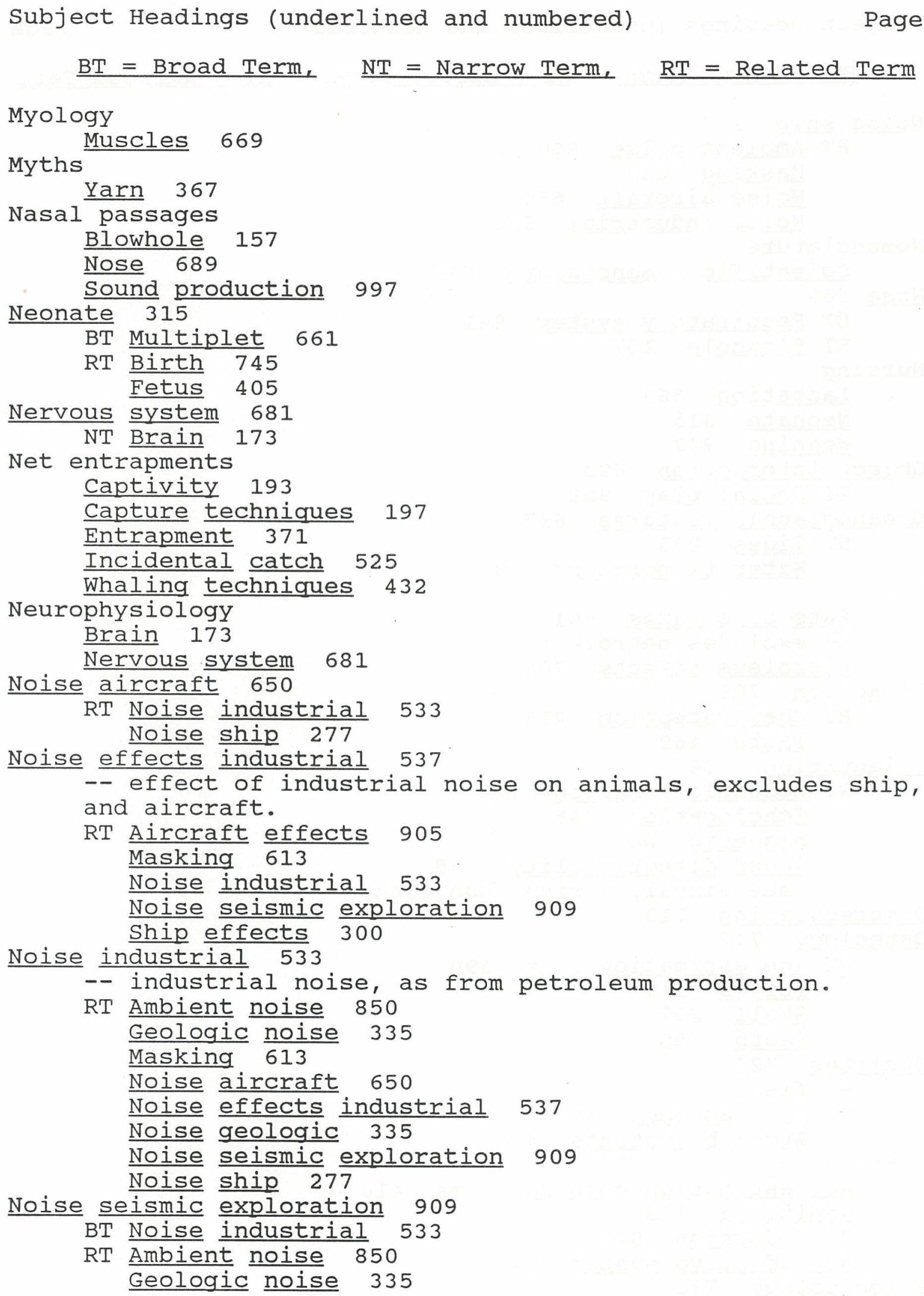


Subject Headings (underlined and numbered)

Page 23

$\underline{\mathrm{BT}}=$ Broad Term, $\quad \underline{\mathrm{NT}}=$ Narrow Term, $\underline{\mathrm{RT}}=$ Related Term

Noise ship 277

RT Ambient noise 850

Masking 613

Noise aircraft 650

Noise industrial 533

Nomenclature

Scientific nomenclature 685

Nose 689

BT Respiratory system 861

Nursing

RT Blowhole 157

Lactation 569

Neonate 315

Weaning 742

object interaction 693

BT Social play 958

oceanographic features 697

NT Tides 238

Oil

Water temperature 539

Fats oils waxes 401

-- excludes petroleum. Petroleum effects 701

Olfaction 705

RT Chemoreception 213

Taste 469

orientation 709

RT Acoustic location 170

Echolocation 345

Magnetic 602

Sound directionality 985 see visual, various subjects.

Osmoregulation 713

Osteology 717

NT Age estimation bone 390

Pelvis 319

Skull 257

Teeth 755

Otoliths 721

-- fish.

RT Fish as food 425

Ovaries Stomach contents 486

Age estimation corpora lutea 410

Genitalia 453

Reproduction 845

Reproductive system 849

Paleontology 733

RT Evolution 385 
Subject Headings (underlined and numbered)

$\underline{\mathrm{BT}}=$ Broad Term, $\underline{\mathrm{NT}}=$ Narrow Term, $\underline{\mathrm{RT}}=$ Related Term

Parasites

Cyamids 269

Ectoparasites 349

Endoparasites $\quad 365$

Parental 617

-- investment, attendance behavior, rearing strategies.

RT Allomaternal 760

Birth 745

Care giving 201

Juvenile 557

Neonate 315

Social behavior 957

Parturition

Weaning 742

Birth 745

Pathology 749

NT Blindness 149

Healing 485

Teratology 811

Pelvis 319

BT Osteology 717

Penis

RT Evolution 384

Genitalia 453

Mating 621

Reproductive system 849

Sexual behavior 929

Petroleum effects 701

RT Contaminants 245

Phonation 761

-- sounds produced with air mechanisms.

NT $\mathrm{Call} \quad 174$

Click 221

Coda 225

Dialect 289

Distress call 309

Echolocation 345

Signature signal 953

Song 965

Whistle 395

RT Acoustic communication 900

Fish sounds 417

Harmonic 473

Sound directionality 985

-- propagation.

Sound production 997

Photo period 273

RT Diel 293

Photography techniques 765 
Subject Headings (underlined and numbered)

$$
\underline{\mathrm{BT}}=\text { Broad Term, } \underline{\mathrm{NT}}=\text { Narrow Term, } \underline{\mathrm{RT}}=\text { Related Term }
$$

Physiology

Auditory physiology 121

Body temperature 159

Digestive system 301

Diving physiology 325

Metabolism 637

Nervous system 681

Osmoregulation 713

Respitory system 861

Thermoregulation 583

Vascular system 223

Picture

Visual physiology 825

-- a separate database field (PI).

Photography techniques 765

Pigmentation 233

RT Albinism 730

Field marks 413

Healing 485

Individual identification 529

Pinger 777




Subject Headings (underlined and numbered)

Page 26

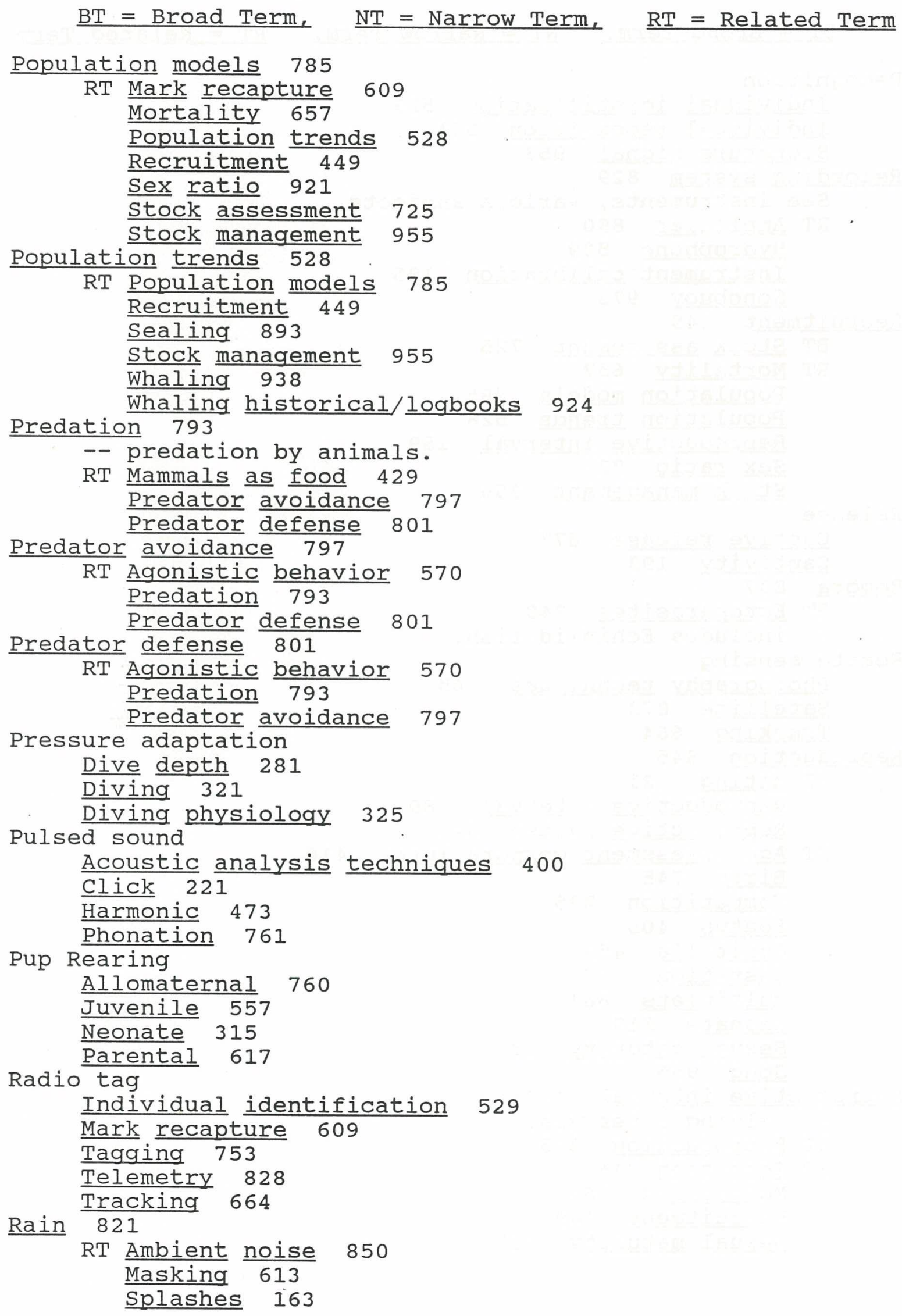


Subject Headings (underlined and numbered)

$$
\underline{\mathrm{BT}}=\text { Broad Term }, \quad \underline{\mathrm{NT}=\text { Narrow Term, }} \underline{\mathrm{RT}=\text { Related Term }}
$$

Recognition

Individual identification 529

Individual recognition 531

Signature signal 953

Recording system 829

See instruments, various subjects.

RT Amplifier 890

Hydrophone 509

Instrument calibration 185

Sonobuoy 973

Recruitment 449

BT Stock assessment 725

RT Mortality 657

Population models 785

Population trends 528

Reproductive interval 189

Sex ratio 921

Stock management 955

Release

Captive release 677

Captivity 193

Remora 837

BT Ectoparasites 349

-- includes Echiniid fish.

Remote sensing

Photography techniques 765

Satellite 873

Tracking 664

Reproduction 845

NT Mating 621

Reproductive interval 189

Reproductive system 849

RT Age assessment corpora lutea 410

Birth 745

Competition 235

Foetus 405

Genitalia 453

Gestation 457

Multiplets 661

Neonate 315

Sexual maturity 989

Song 965

Reproductive interval 189

- calving intervals.

BT Reproduction 845

RT Gestation 457

Multiplets 661

Recruitment 449

Sexual maturity 989 
Subject Headings (underlined and numbered)

$$
\underline{\mathrm{BT}}=\text { Broad Term, } \underline{\mathrm{NT}}=\text { Narrow Term, } \quad \underline{\mathrm{RT}}=\text { Related Term }
$$

Reproductive system 849

-- includes ovaries, testes.

NT Genitalia 453

Gestation 457

Mating 621

BT Reproduction 845

RT Sexual behavior 929

Respiration

Sexual maturity 989

Blow 153

Lungs 317

Respiration rate 857

Respiration system 861

Respiration rate 857

-- blow rates and numbers, surface time,

RT Blow 153

Metabolism 637

Respiratory system 861

Underwater blow 817

Respiratory system 861

-- includes anatomy, tidal volume.

NT Blowhole 157

Lung 317

Nose 689

RT Blow 153

Respiration rate 857

Underwater blow 817

Resting behavior 863

RT Sleep 927

Review 169

-- reviews of specific publications.

Cetacean general 171

-- general information.

RT Literature review 593

-- subject review.

Pinniped general 118

Salinity tolerance

-- general information.

Osmoregulation 713

Satellite 873

-- satellite monitoring of radio tags, remote sensing.

BT Telemetry 828

Tracking 664

RT Mark recapture 609

Savssat

Ice 513

Ice entrapment 877 
Subject Headings (underlined and numbered)

$\underline{\mathrm{BT}}=$ Broad Term, $\underline{\mathrm{NT}=\text { Narrow Term, }} \underline{\mathrm{RT}=\text { Related Term }}$

Scars

Field marks 413

Healing 485

Individual identification 529

Pathology 749

Pigmentation 233

scattering layer 885

RT Fish as food 425

Food 422 , various subjects. Sonar 961

Swim bladder 888

Schooling 889

RT Feeding 404 , various subjects

Fish as food 425

Lunge feeding 406

Scientific nomenclature 685

RT Dolphin porpoise 329

Keys 561

Systematics 978

Taxonomic diagnosis 287

Sea story

Collector's troubles 397

Yarn 367

Sealing 893

RT Pinniped general 118

Whaling 938

Seasonal occurrence 897

RT Geographic distribution 455

Home range 493

Territoriality 700

Secondary sexual characters

Sex ratio 921

Sexual dimorphism 933

Senses

Sexual maturity 989

Chemoreception 213

Hearing 487

In air hearing 521

In air vision 523

Magnetic 602

Olfaction 705

Taste 469

Touch 800

Underwater vision 445

Serology

Blood 917

Vascular system 223

Sex determination 925

RT Genetics 452

Karyotype 883 
Subject Headings (underlined and numbered)

$$
\underline{\mathrm{BT}}=\text { Broad Term, } \underline{\mathrm{NT}}=\text { Narrow Term, } \underline{\mathrm{RT}}=\text { Related Term }
$$

Sex ratio 921

RT Genetics 452

Multiplets 661

Mortality 657

Population models 785

Recruitment 449

Sexual behavior 929

-- excluding copulation.

NT Mating 621

- copulation.

RT Reproduction 845

Social behavior 957

Sexual dimorphism 933

Sexual grouping

Social organization 959

Sexual maturity 989

RT Growth rate 465

Reproduction 845

Shark marine mammal 941

BT Mixed species 645

RT Predator avoidance 797

Predator defence 801

Ship effects 300

NT Whale watching 841

RT Aircraft effects 905

Noise effects industrial 537

Sight

Noise ship 277

Eye 880

In air vision 523

Underwater vision 445

Visual communication 237

Visual physiology 825

Sightings

Field observations 451

Geographic distribution 455

Signature signal 953

-- individual identity sounds.

NT Coda 225

BT Phonation 761

RT Individual identification 529

Individual recognition 531

Size Voice 377

Dimensions 305

Weight in air 418

Weight in water 819

Whaling statistics 167

Skeleton

Osteology 717

Skull 257 
Subject Headings (underlined and numbered)

$$
\underline{\mathrm{BT}}=\text { Broad Term, } \underline{\mathrm{NT}}=\text { Narrow Term, } \underline{\mathrm{RT}}=\text { Related Term }
$$

Skim Feeding 407

BT Feeding 404

RT Food 422

$$
\text { Plankton as food } 433
$$

Skin (and blubber) 373

RT Blubber 161

$$
\text { Callosities } 165
$$

Dermal hardening 285

Skul1 257

$$
\text { Hydrodynamic } 505
$$

Molt 254

BT Osteology 717

Sleep 927

RT Resting behavior 863

Social behavior 957

RT Dominance hierarchy 333

\section{Parental 617}

Sexual behavior 929

Social organization 959

Social play 958

Social learning 956

BT Learning 582, various subjects

RT Imitation 517

Vocal learning 548

Social organization 959

RT Dominance hierarchy 333

$$
\text { Social behavior } 957
$$

Social play 958

NT Object interaction 693

RT Social behavior 957

Sonar 961

-- sound echo-ranging by humans.

RT Echolocation 345

Scattering layer 885

Swim bladder 888

Target strength 342

Song 965

-- animal phonations as song.

BT Phonation 761

RT Reproduction 845

Sexual behavior 929

Sonobuoy 973

Sound

RT Hydrophone 509

Acoustic analysis techniques 400

Acoustic location 170

Ambient noise 850

Amplifier 426

Audiogram 109

Blow 153

Echolocation 345

Fish sounds 417 
Subject Headings (underlined and numbered)

$\underline{\mathrm{BT}}=$ Broad Term,$\quad \underline{\mathrm{NT}}=$ Narrow Term, $\quad \underline{\mathrm{RT}}=$ Related Term

Sound (continued)

Geologic noise 335

Hearing 487

Hydrodynamic sound 507

Hydrophone 509

In air hearing 521

In air sounds 522

Individual recognition 531

Lateral line 581

Masking 613

Noise aircraft 650

Noise effects industrial 537, various subjects

Noise industrial 533

Noise seismic exploration 909

Noise ship 277

Phonation 761, various subjects

Pinger 777

Playback 781

Recording system 829

Scattering layer 885

Signature signal 953

Sonar 961

Song 965

Sonobuoy 973

Sound directionality 985

Sound production 997

Sound projector 805

Sound propagation 444

Sound source level 555

Splashes 163

Swim bladder 888

Tank acoustics 111

Target strength 342

Voice 377

Sound analysis

Acoustic analysis techniques 400

Sound channel

oceanographic features 697

Sound propagation 444

sound directionality 985

-- directional propagation of sound.

RT Echolocation 345

Directional hearing 993

Echolocation 345

orientation 709

Phonation 761

Sound propagation 444 
Subject Headings (underlined and numbered)

$$
\underline{\mathrm{BT}}=\text { Broad Term }, \quad \underline{\mathrm{NT}}=\text { Narrow Term, } \quad \underline{\mathrm{RT}}=\text { Related Term }
$$

Sound gear

See instruments, various subjects.

Amplifier 890

Hydrophone 509

Pinger 777

Recording system 829

Sonar 961

Sonobuoy 973

Sound projector 805

Sound localization

Acoustic location 170

Sound directionality 985

Sound propagation 444

Sound source level 555

Sound production 997

-- mechanisms of sound production by animals.

RT Aerial behavior 250

Blow 153

Breaching 177

Echolocation 345

Hydrodynamic sound 507

Phonation 761, various subjects

Playback 781

Sound directionality 985

Sound propagation 444

Splashes 163

Sound projector 805

RT Playback 781

Sound source level 555

Sound propagation 444

NT Sound directionality 985

RT Oceanographic features 697

Sound production 997

Sound projector 805

sound scattering

Scattering layer 885

Sonar 961

Swim bladder 888

Target strength 342

Sound source level 555

-- measure of absolute sound levels.

RT Instrument calibration 185

Phonation 761

Sound production 997

Sound projector 805

Sound propagation 444

Target strength 342

sound velocity

Oceanographic features 697

Sound propagation 444 
Subject Headings (underlined and numbered)

$$
\underline{B T}=\text { Broad Term, } \underline{\text { NT }=\text { Narrow Term, }} \underline{\text { RT }=\text { Related Term }}
$$

Source level

Sound propagation 444

Sound source level 555

Target strength 342

Special gear

Equipment special 375

Speed 780

-- movement.

RT Locomotion 597

Wave riding 160

Spermaceti 464

BT Fats oils waxes 401

RT Melon 629

Splashes 163

RT Aerial behavior 250

Ambient noise 850

Breaching 177

Fluking 424

Rain 821

Spout

Sound production 997

Blow 153

Spyhopping

-- pitchpoling.

Aerial behavior 250

Squid as food 437

BT Food 422

RT Ambergris 810

Squeal

Phonation 761

Whistle 395

Stock assessment 725

-- abundance estimates, stock delineation.

NT Acoustic census 5

RT Census techniques 205

Geographic distribution 455

Mark recapture 609

Mortality 657

Population models 785

Population trends 528

Recruitment 449

Seasonal occurrence 897

Stock management 955

Stock management 955

-- control of population.

RT Population models 785

Recruitment 449

Sealing 893

Whaling 938 
Subject Headings (underlined and numbered)

$$
\underline{\mathrm{BT}}=\text { Broad Term, } \underline{\mathrm{NT}=\text { Narrow Term, }} \underline{\mathrm{RT}=\text { Related } \text { Term }}
$$

Stomach contents 486

RT Diet 295

Feeding 404

Food 422, various subjects

otoliths 721

stranding dead 931

BT Mortality 657

RT Pathology 749

Stranding live 665

Stranding live 665

RT Mortality 657

Pathology 749

Stranding dead 931

Strip census

Census techniques 205

Suction feeding 408

BT Feeding 404

RT Food 422, various subjects

Swim bladder 888

RT Echolocation 345

Fish as food 425

Scattering layer 885

Sonar 961

Swimming

Target strength 342

Locomotion 597

Speed 780

Wave riding 160

Symbiosis 222

Systematics 978

RT Keys 561

Scientific nomenclature 685

Tactile

Taxonomic diagnosis 287

Touch 800

Tagging 753

-- includes "Discovery marking".

NT Age estimation tag returns 490 Individual identification 529 (natural marks) Telemetry 828

BT Tracking 664

RT Mark recapture 609

Tail 869

-- tail stock, the "small", "peduncle".

RT Flukes 421

Locomotion 597

Tank acoustics 111 
Subject Headings (underlined and numbered)

$$
\underline{\mathrm{BT}}=\text { Broad Term }, \quad \underline{\mathrm{NT}}=\text { Narrow Term, } \quad \underline{\mathrm{RT}}=\text { Related Term }
$$

Target Discrimination

Echolocation 345

Directional hearing 993

Hearing 487

Sonar 961

Target strength 342

Underwater vision 445

Target strength 342

BT Echolocation 345

Sonar 961

RT Scattering layer 885

$$
\text { Sound source level } 555
$$

Taste 469

See senses, various subjects.

RT Chemoreception 213

olfaction 705

Taxonomic diagnosis 287

RT Keys 561

Scientific Nomenclature 685

Taxonomy Systematics 978

Systematics 978

Taxonomic Diagnosis 287

Teeth 755

NT Age estimation teeth 530

RT Osteology 717

Telemetry 828

-- transfer of information from a distance, usually by

other means than the primary signal of a device.

BT Tagging 753

RT Satellite 873

Tracking 664

Temperature

Body temperature 159

Water temperature 539

Teratology 811

-- abnormal formations in marine mammals.

BT Pathology 749

Territoriality 700

RT Competition 235

Geographic distribution 455

Home range 493

Seasonal occurrence 897

Testes

Genitalia 453

Sexual maturity 989

Reproductive system 849

Theodolite 112

RT Equipment special 375

-- see instruments. 
Subject Headings (underlined and numbered)

$$
\underline{\mathrm{BT}}=\text { Broad Term, } \underline{\mathrm{NT}}=\text { Narrow Term, } \underline{\mathrm{RT}}=\text { Related Term }
$$

Thermorequlation 583

-- see physiology, various subjects.

NT Body temperature 159

RT Water temperature 539

Throat (and mouth) 249

RT Feeding 404

$$
\text { Mouth } 660
$$

Tidal volume

$$
\text { Ventral grooves } 673
$$

Blow 153

Lung 317

Respiratory system 861

Tides 238

RT Oceanographic features 697

Tongue

Feeding 404

Mouth 660

Throat 249

Ventral grooves 673

Touch 800

RT Vibrissae 631

-- see senses, various subjects.

Tracking 664

NT Age estimation tag returns 490

Individual identification 529

Satellite 873

Tagging 753

Telemetry 828

Training 915

-- human training of animals.

Tuna marine mammal 357

BT Mixed species 645

Incidental catch 525

Tuna porpoise

Incidental catch 525

Tuna marine mammal 357

Underwater blow 817

BT Blow 153

RT Respiration rate 857 Respiratory system 861

Underwater hearing

Ear 113

Hearing 487

In air hearing 521 .

Underwater vision 445

-- see visual, various subjects.

RT Eye 880. In air vision 523

Vascular system 223

RT Blood 917

Heart 489 
Subject Headings (underlined and numbered)

$\underline{\mathrm{BT}}=$ Broad Term, $\underline{\mathrm{NT}=\text { Narrow Term }, \quad \underline{\mathrm{RT}}=\text { Related Term }}$

Velocity

Locomotion 597

Sound propagation 444

Speed 780

Ventral grooves 673

RT Feeding 404

Mouth 660

Throat 249

Vernacular names

-- not a subject category. See listing of vernacular names

in species List and search for scientific name in

Genus/Species (GS) Field.

Vestigial organs 210

Vibrissae 631

RT Hair 471.

Video 265 Touch 800

Viscera 215

Vision

Eye 880

In air vision 523

Underwater vision 445

Visual communication 237

Visual physiology 825

Visual communication 237

RT Eye 880

In air vision 523

Underwater vision 445

Visual physiology 825

NT Eye 880

Vocal learning 548

BT Learning 582

RT Imitation 517

Vocalization

Phonation 761, various subjects

Voice 377

-- distinctive sound features produced by innate vocal

mechanism characteristics, not cetacean signature signals.

RT Individual identification 529

Individual recognition 531

Water depth

Signature signal 953

Dive depth 281

Diving 321

oceanographic features 697

Water temperature 539

BT Oceanographic features 697

RT Thermoregulation 583

Wave noise

Ambient noise 805

Splashes 163 
Subject Headings (underlined and numbered)

$$
\underline{\mathrm{BT}}=\text { Broad Term, } \underline{\mathrm{NT}}=\text { Narrow Term, } \quad \underline{\mathrm{RT}}=\text { Related Term }
$$

Wave riding 160

RT Locomotion

597

Weaning 742

RT Age and growth 314

Juvenile 557

Lactation 569

Parental 617

Weight in air 418

Weight in water 819

Whale watching 841

BT Ship effects 300

Whaling 938

NT Whaling historical/logbooks 924

Whaling quotas 794

Whaling statistics 167

Whaling guotas 794

Whaling statistics 167

Whaling techniques 432

RT Capture techniques 197

Cetacean general 171

Population trends 528

Sealing 893

Whaling commission

IWC 553

Whaling historical/logbooks 924

BT Whaling 938

RT Population trends 528

Whaling statistics 167

Whaling quotas 794

BT Whaling 938

RT Population trends 528

Whaling statistics 167

Whaling statistics 167

BT Whaling 938

RT Population trends 528

Whaling historical/logbooks 924

Whaling techniques 432

BT Whaling 938

Whistle 395

Wind

BT Phonation 761

Ambient noise 850

Splashes 163

Yarn 367

-- Myths, sea stories.

RT Collector's troubles 397

Zoogeography

RT Geographic distribution 455

Home range 493

Seasonal occurrence 897

Territoriality 700 
i

(4)

$\frac{2}{2}$

6

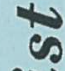

is

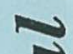

e

(2)

0

2

눈 
ALPHABETICAL LISTING OF SUBJECT HEADINGS

For the Reference Database 


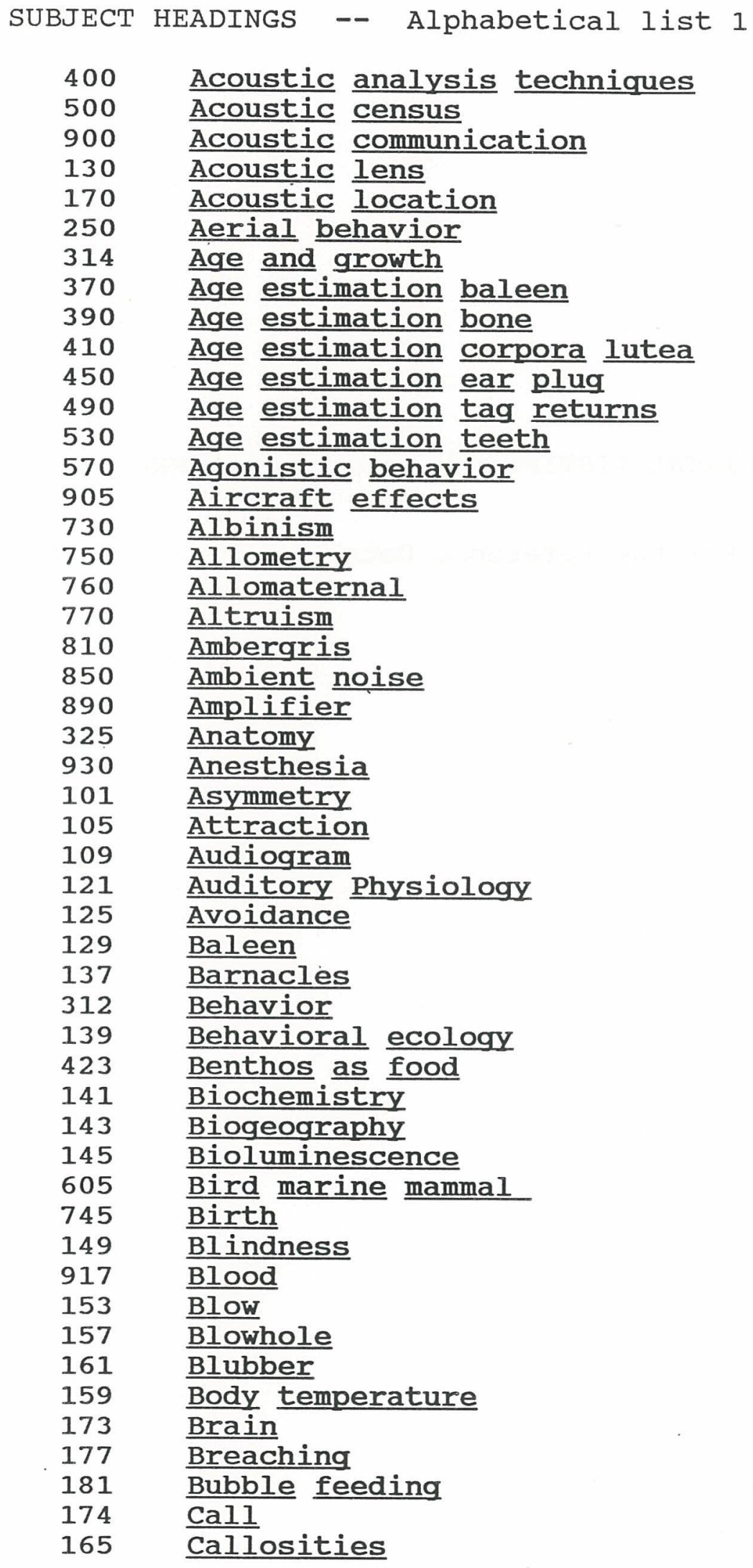




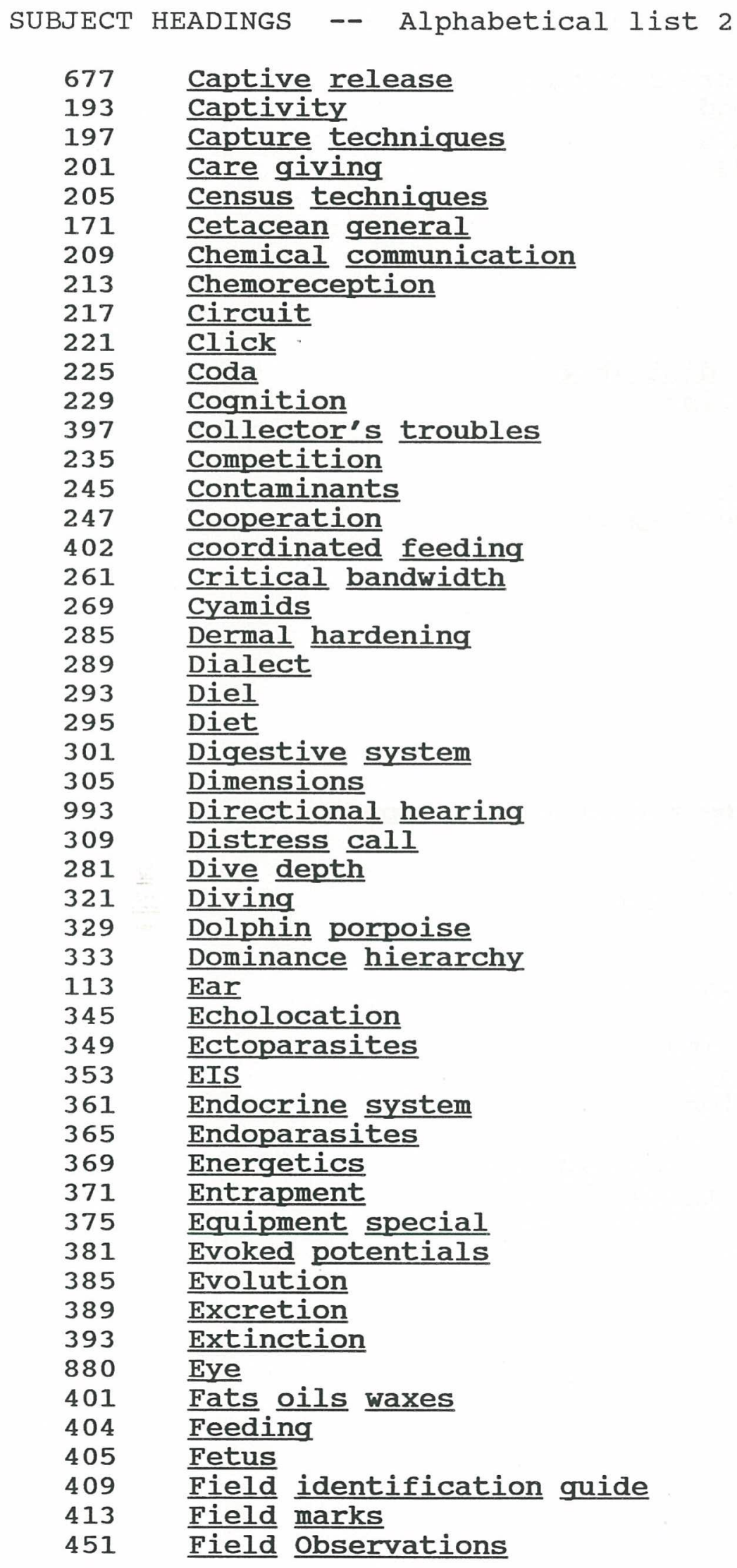




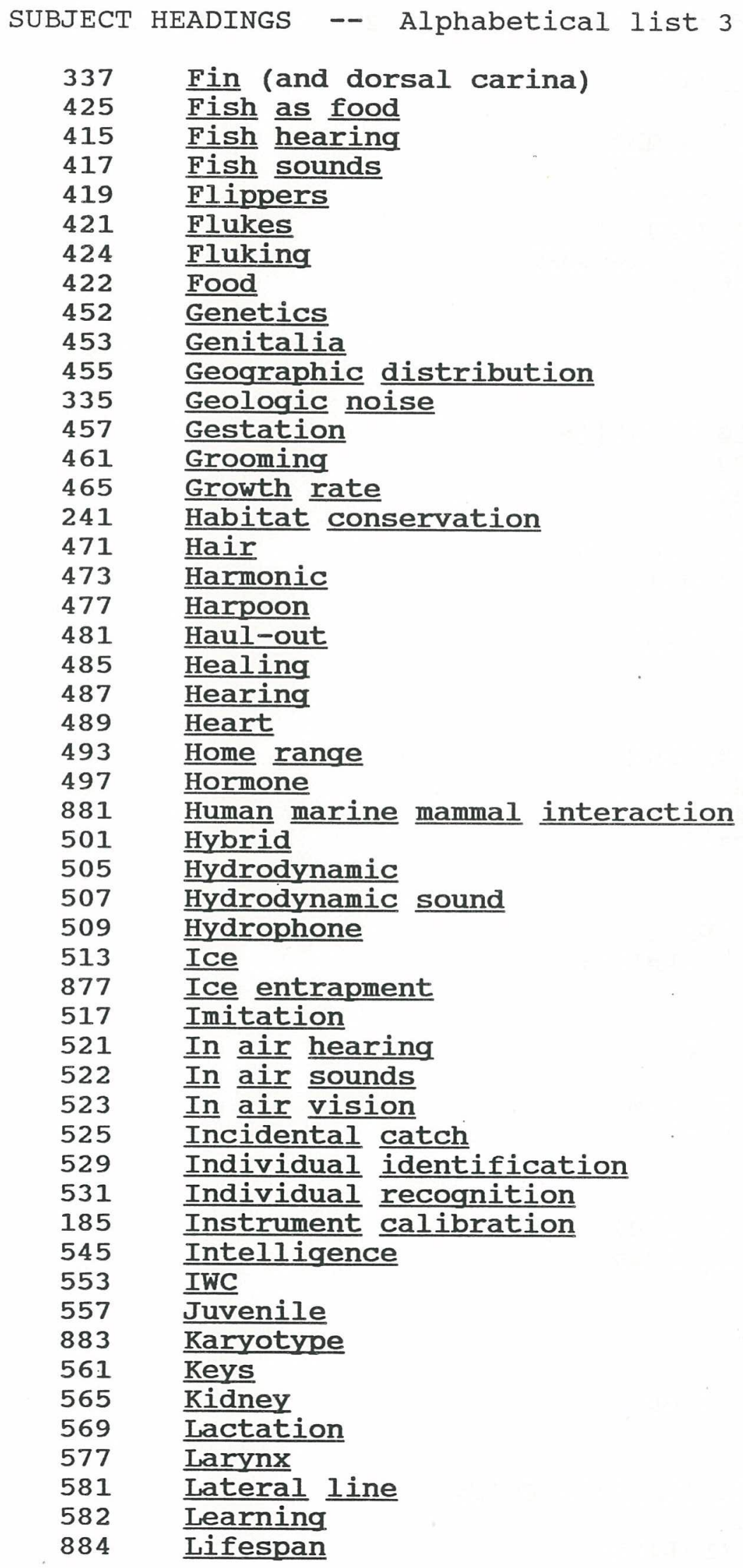




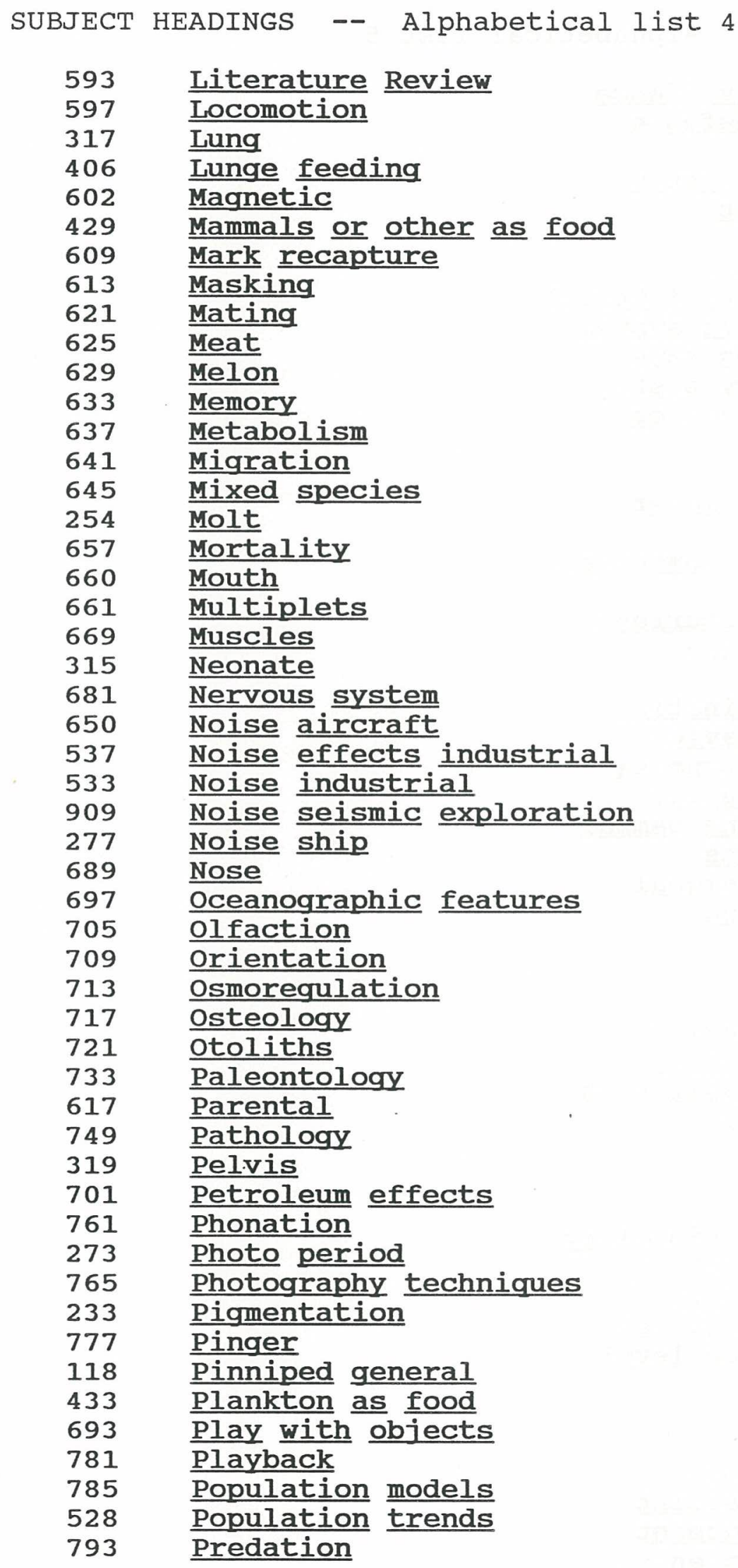


SUBJECT HEADINGS -- Alphabetical list 5

\begin{tabular}{|c|c|}
\hline 797 & Predator avoidance \\
\hline 801 & Predator defense \\
\hline 821 & Rain \\
\hline 829 & Recording system \\
\hline 449 & Recruitment \\
\hline 837 & Remora \\
\hline 845 & Reproduction \\
\hline 189 & Reproductive interval \\
\hline 849 & Reproductive system \\
\hline 857 & Respiration rate \\
\hline 861 & Respiratory system \\
\hline 863 & Resting behavior \\
\hline 169 & Review \\
\hline 873 & Satellite \\
\hline 885 & Scattering layer \\
\hline 889 & Schooling \\
\hline 685 & Scientific nomenclature \\
\hline 893 & Sealing \\
\hline 897 & Seasonal occurrence \\
\hline 909 & Seismic noise \\
\hline 921 & Sex ratio \\
\hline 925 & Sex determination \\
\hline 929 & Sexual behavior \\
\hline 933 & Sexual dimorphism \\
\hline 989 & Sexual maturity \\
\hline 941 & Shark marine mammal \\
\hline 300 & Ship effects \\
\hline 953 & Signature signal \\
\hline 407 & Skim Feeding \\
\hline 373 & Skin \\
\hline 257 & skul1 \\
\hline 927 & Sleep \\
\hline 957 & Social behavior \\
\hline 956 & Social learning \\
\hline 959 & Social organization \\
\hline 958 & Social play \\
\hline 961 & Sonar \\
\hline 965 & Song \\
\hline 973 & Sonobuoy \\
\hline 985 & Sound directionality \\
\hline 997 & Sound production \\
\hline 805 & Sound projector \\
\hline 444 & Sound propagation \\
\hline 555 & Sound source level \\
\hline 780 & Speed \\
\hline 464 & Spermaceti \\
\hline 163 & Splashes \\
\hline 437 & Squid as food \\
\hline 725 & Stock assessment \\
\hline 955 & Stock management \\
\hline 486 & Stomach contents \\
\hline
\end{tabular}




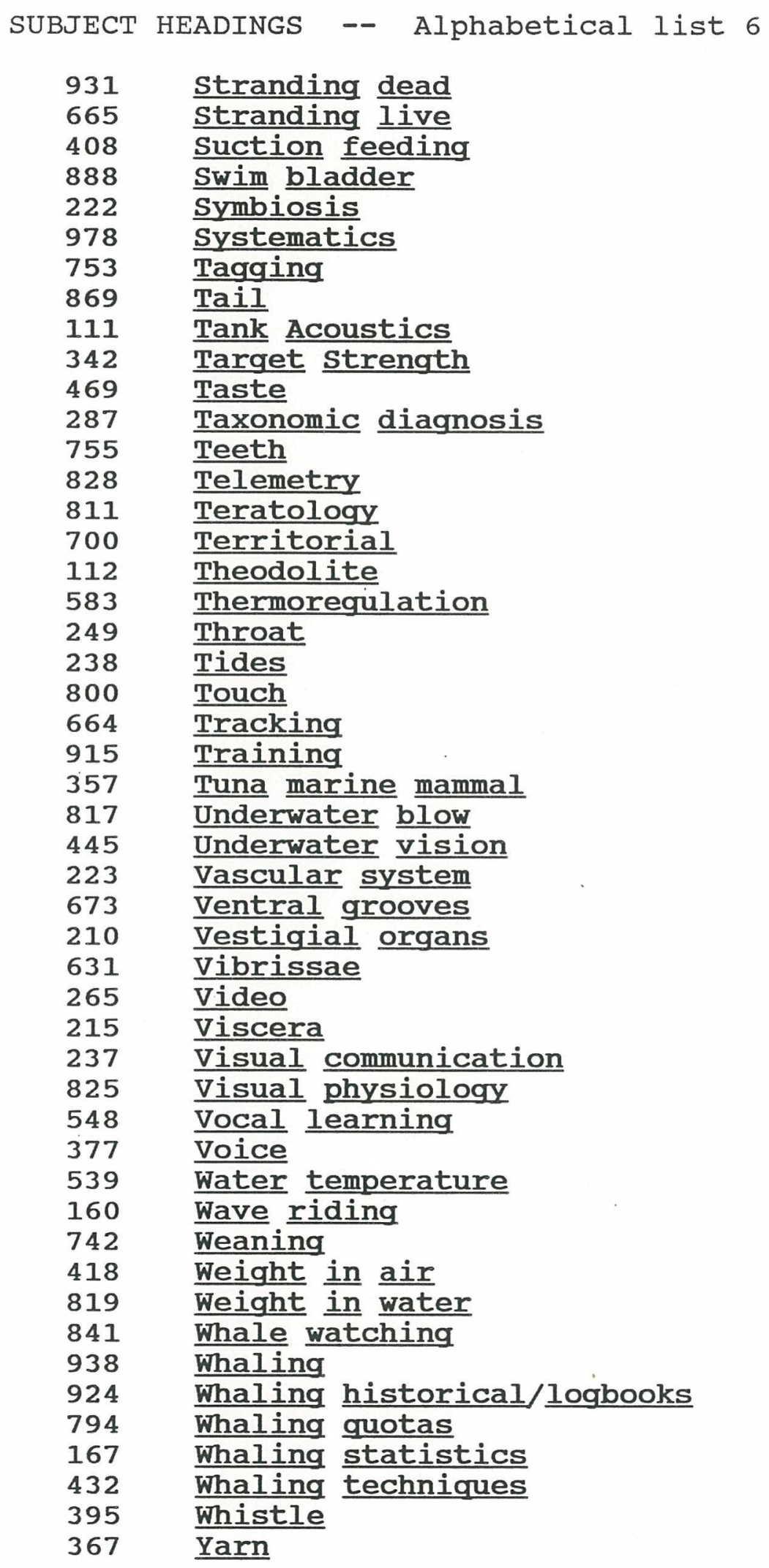


$-\infty$

1



8

$\frac{\pi}{2}$ 
NUMERICAL SEQUENCE OF SUBJECT HEADINGS

For the Reference Database 


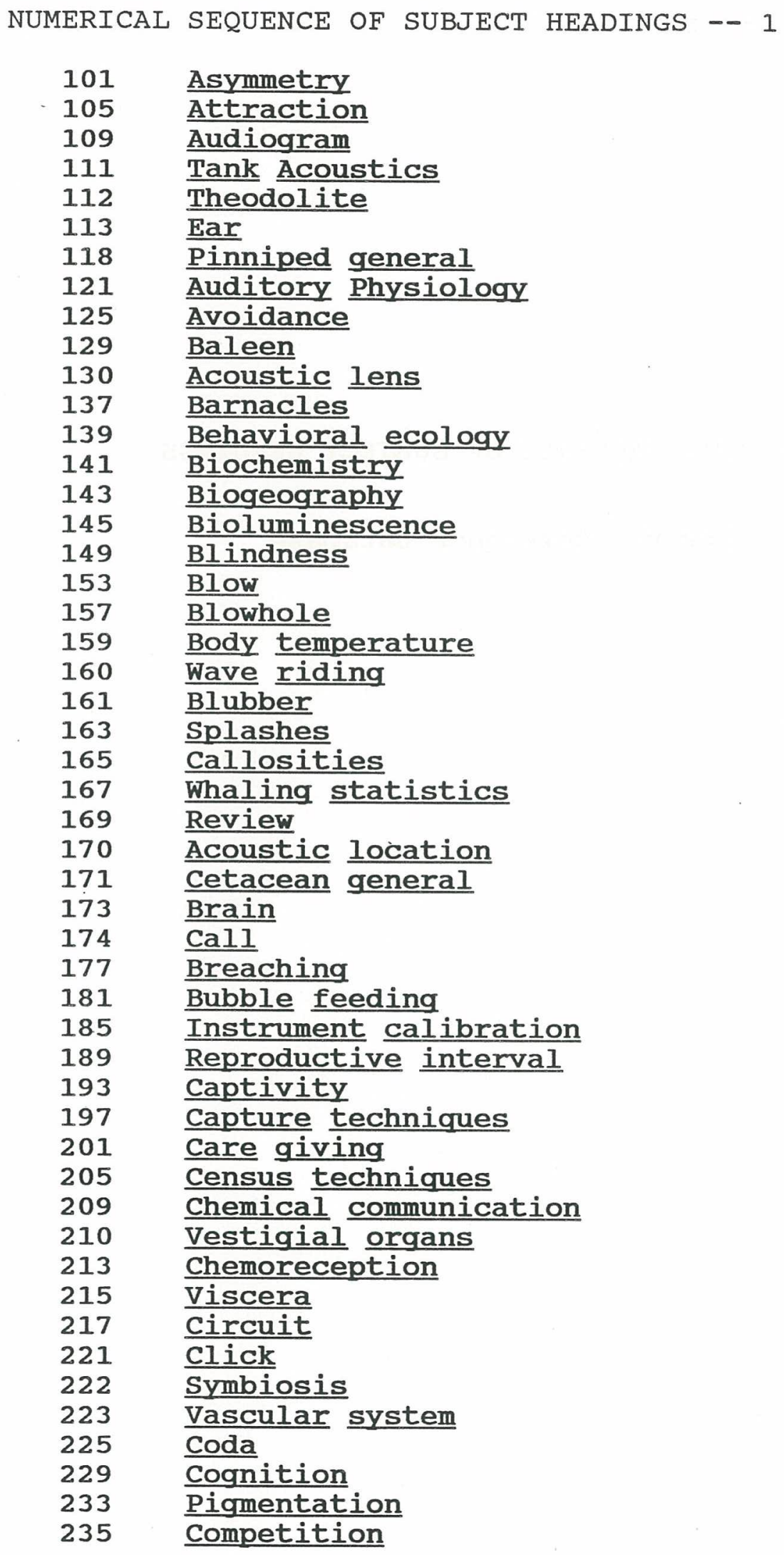


NUMERICAL SEQUENCE OF SUBJECT HEADINGS -- 2

\begin{tabular}{|c|c|}
\hline 237 & Visual communication \\
\hline 238 & Tides \\
\hline 241 & Habitat conservation \\
\hline 245 & Contaminants \\
\hline 247 & Cooperation \\
\hline 249 & Throat \\
\hline 250 & Aerial behavior \\
\hline 254 & Molt \\
\hline 257 & $\overline{\text { Skull }}$ \\
\hline 261 & Critical bandwidth \\
\hline 265 & Video \\
\hline 269 & Cyamids \\
\hline 273 & Photo period \\
\hline 277 & Noise ship \\
\hline 281 & Dive depth \\
\hline 285 & Dermal hardening \\
\hline 287 & Taxonomic Diagnosis \\
\hline 289 & Dialect \\
\hline 293 & $\underline{\text { Diel }}$ \\
\hline 295 & $\underline{\text { Diet }}$ \\
\hline 300 & Ship effects \\
\hline 301 & Digestive system \\
\hline 305 & Dimensions \\
\hline 309 & Distress call \\
\hline 312 & Behavior \\
\hline 314 & Age and growth \\
\hline 315 & Neonate \\
\hline 317 & Lung \\
\hline 319 & Pelvis \\
\hline 321 & Diving \\
\hline 325 & Anatomy \\
\hline 329 & Dolphin porpoise \\
\hline 333 & Dominance hierarchy \\
\hline 335 & Geologic noise \\
\hline 337 & Dorsal fin (and dorsal carina) \\
\hline 342 & Target strength \\
\hline 345 & Echolocation \\
\hline 349 & Ectoparasites \\
\hline 353 & $\underline{\underline{E I S}}$ \\
\hline 357 & Tuna marine mammal \\
\hline 361 & Endocrine system \\
\hline 365 & Endoparasites \\
\hline 367 & $\underline{\text { Yarn }}$ \\
\hline 369 & Energetics \\
\hline 370 & Age estimation baleen \\
\hline 371 & Entrapment \\
\hline 373 & $\underline{\text { Skin }}$ \\
\hline 375 & Equipment special \\
\hline 377 & Voice \\
\hline 381 & Evoked potentials \\
\hline 385 & Evolution \\
\hline
\end{tabular}




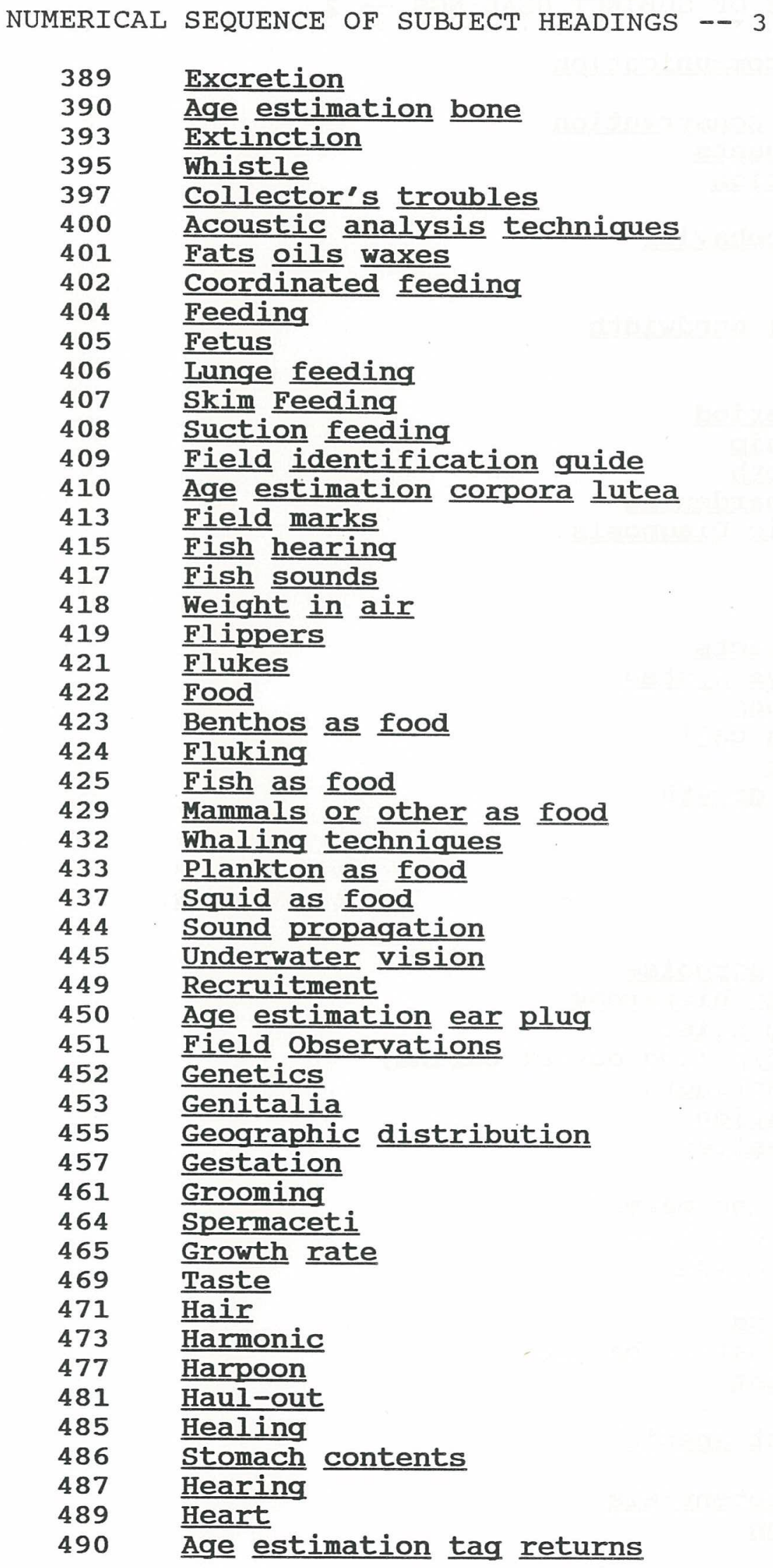




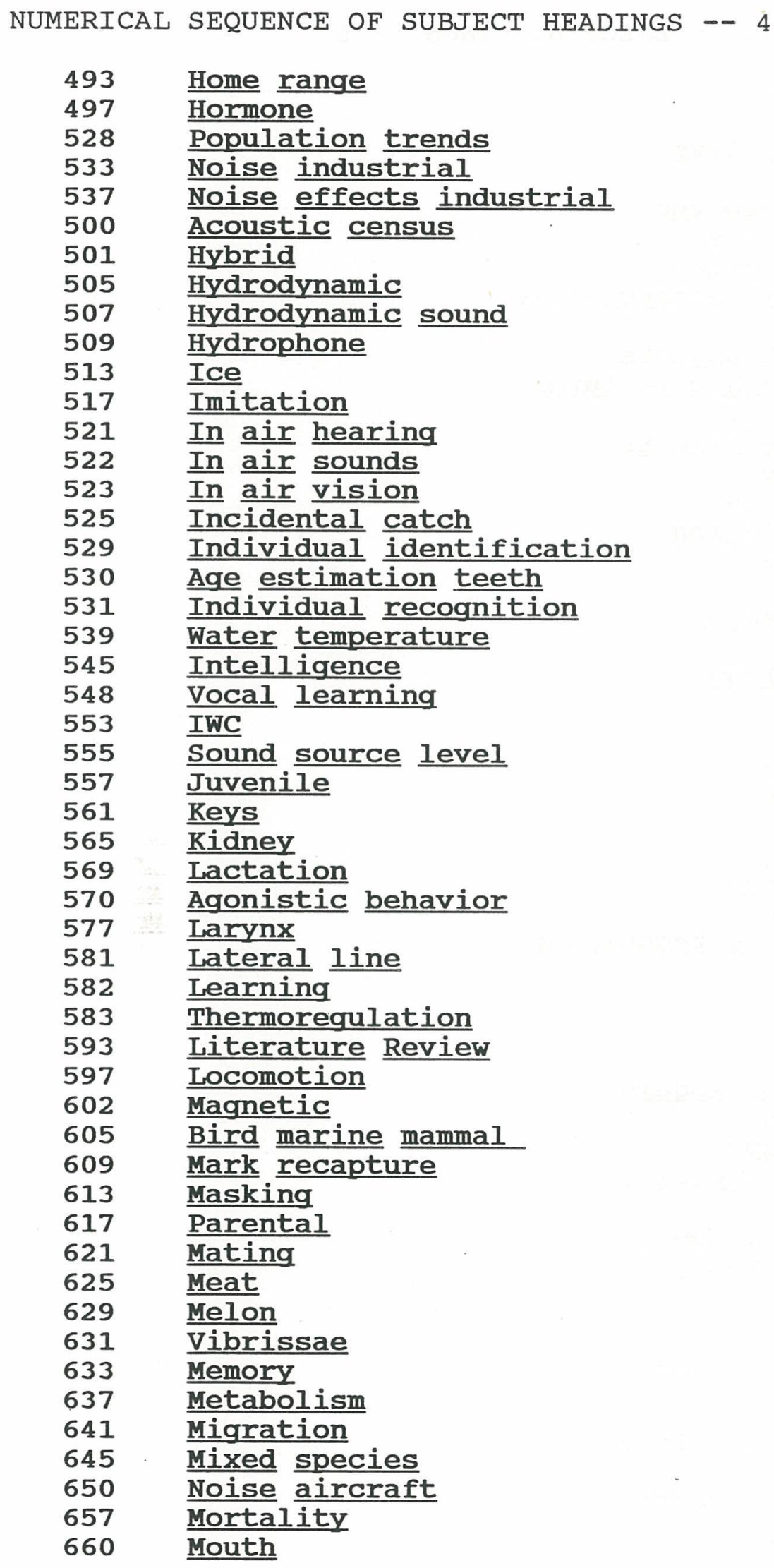




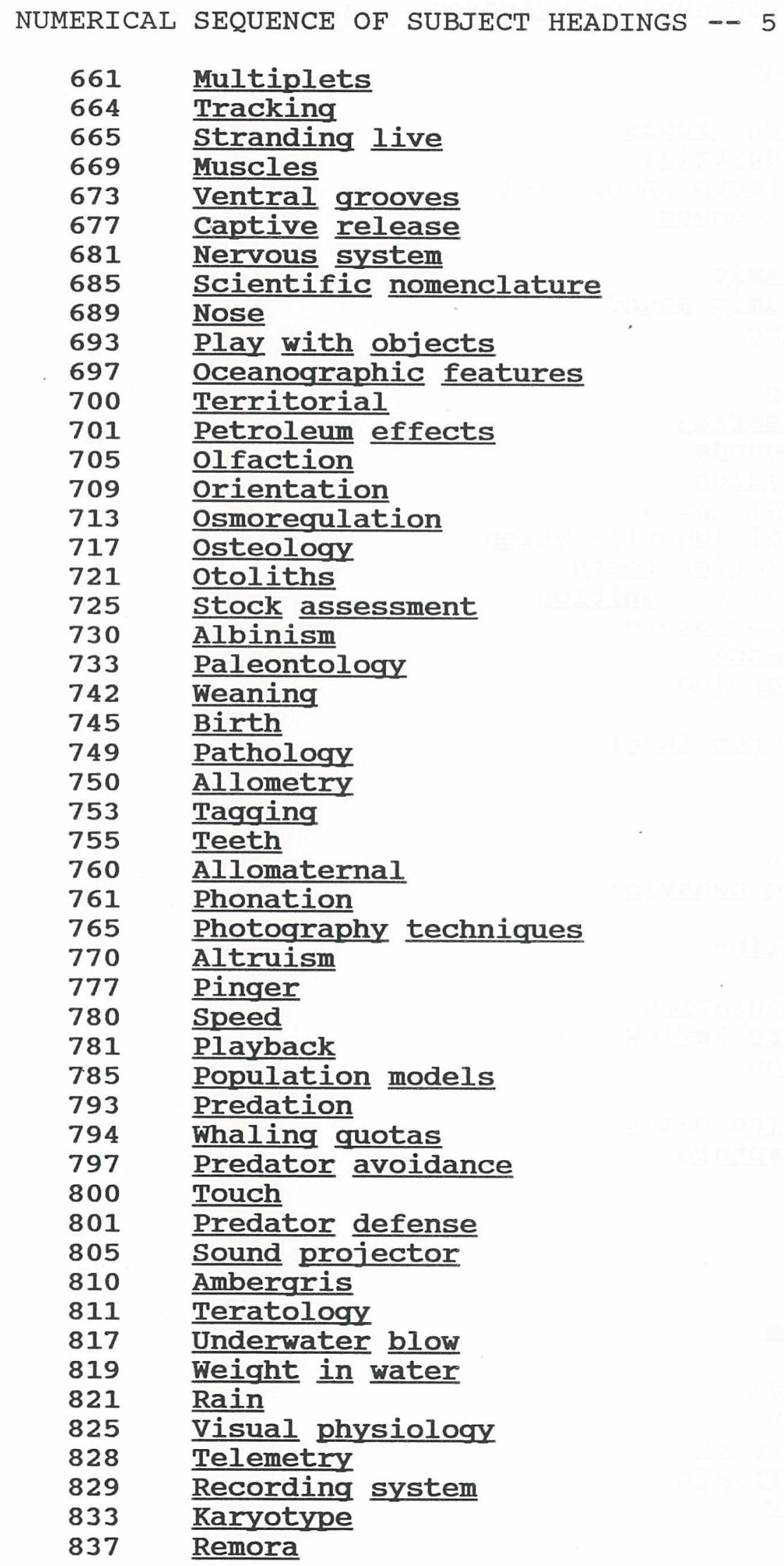




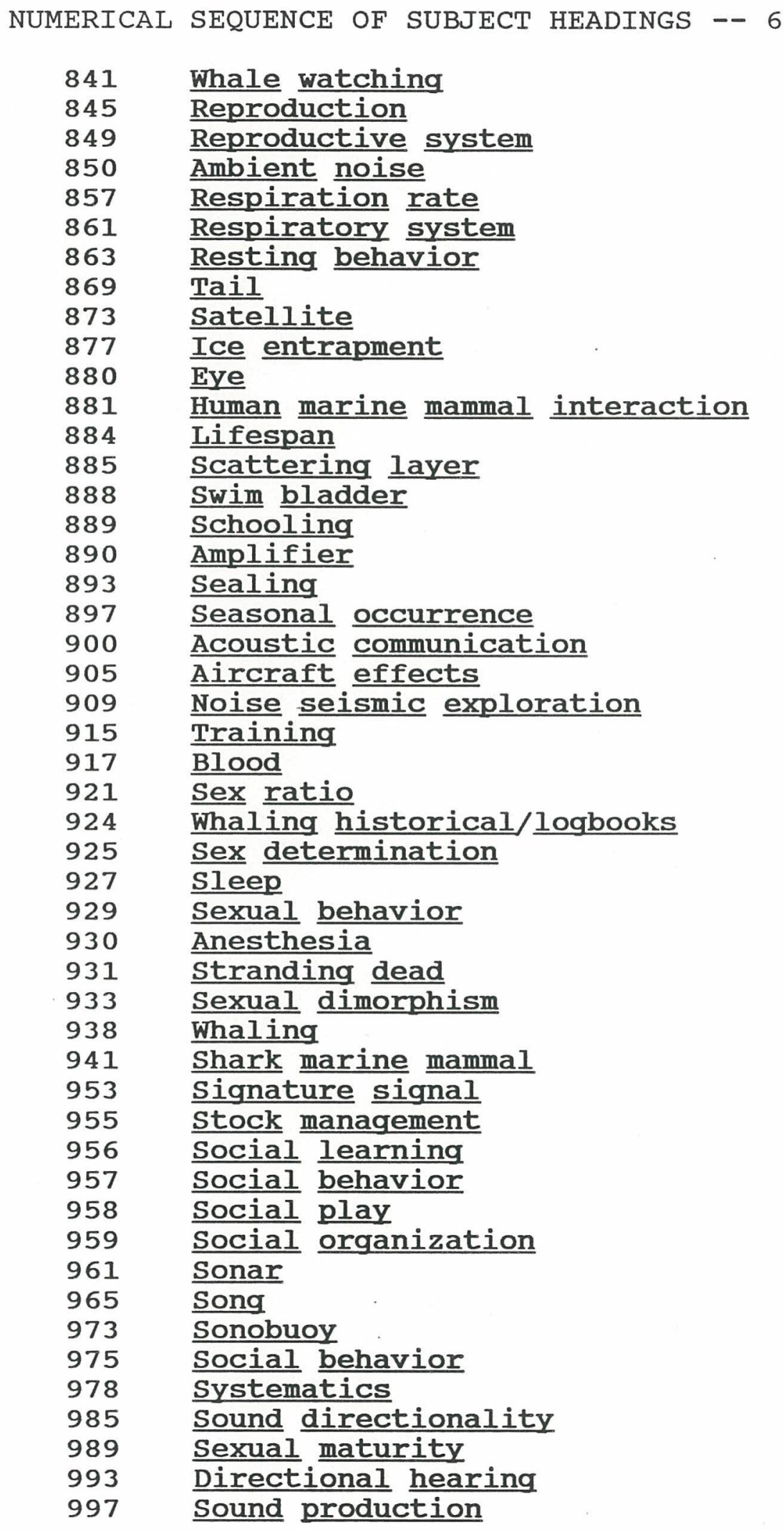


DOCUMENT LIBRARY

August 21, 1987

\section{Distribution List for Technical Report Exchange}

Attn: Stella Sanchez-Wade

Documents Section

Scripps Institution of Oceanography Library, Mail Code C-075C

La Jolla, CA 92093

Hancock Library of Biology \& Oceanography

Alan Hancock Laboratory

University of Southern California

University Park

Los Angeles, CA 90089-0371

Gifts \& Exchanges

Library

Bedford Institute of Oceanography

P.O. Box 1006

Dartmouth, NS, B2Y 4A2, CANADA

Office of the International

Ice Patrol

c/o Coast Guard R \& D Center

Avery Point

Groton, CT 06340

Library

Physical Oceanographic Laboratory

Nova University

8000 N. Ocean Drive

Dania, FL 33304

NOAA/EDIS Miami Library Center

4301 Rickenbacker Causeway

Miami, FL 33149

\section{Library}

Skidaway Institute of Oceanography

P.O. Box 13687

Savannah, GA 31416

Institute of Geophysics

University of Hawaii

Library Room 252

2525 Correa Road

Honolulu, HI 96822

\section{Library}

Chesapeake Bay Institute

4800 Atwell Road

Shady Side, MD 20876

MIT Libraries

Serial Journal Room 14E-210

Cambridge, MA 02139
Director, Ralph M. Parsons Laboratory

Room 48-31 I

MIT

Cambridge, MA 02139

Marine Resources Information Center Building E38-320

MIT

Cambridge, MA 02139

Library

Lamont-Doherty Geological

Observatory

Colombia University

Palisades, NY 10964

Library

Serials Department

Oregon State University

Corvallis, OR 97331

Pell Marine Science Library

University of Rhode Island

Narragansett Bay Campus

Narragansett, RI 02882

Working Collection

Texas A\&M University

Dept. of Oceanography

College Station, TX 77843

Library

Virginia Institute of Marine Science Gloucester Point, VA 23062

Fisheries-Oceanography Library 151 Oceanography Teaching Bldg. University of Washington

Seattle, WA 98195

Library

R.S.M.A.S.

University of Miami

4600 Rickenbacker Causeway

Miami, FL 33149

Maury Oceanographic Library

Naval Oceanographic Office

Bay St. Louis

NSTL, MS 39522-5001 


\begin{tabular}{|c|c|c|}
\hline $\begin{array}{l}\text { REPORT DOCUMENTATION } \\
\text { PAGE }\end{array}$ & $\begin{array}{l}\text { 1. REPORT NO. } \\
\text { WHOI-88-2 }\end{array}$ & 3. Recipient's Accession No. \\
\hline \multirow{2}{*}{\multicolumn{2}{|c|}{$\begin{array}{l}\text { 4. Title and Subtitle } \\
\text { Reference Database } \\
\text { Marine Mammal Literature }\end{array}$}} & $\begin{array}{l}\text { 5. Report Date } \\
\text { January } 1988\end{array}$ \\
\hline & & 6. \\
\hline \multicolumn{2}{|c|}{$\begin{array}{l}\text { William A. Watkins, James E. Bird*, Karen E. Moore, and } \\
\text { Peter Tyack }\end{array}$} & $\begin{array}{l}\text { 8. Performing Organization Rept. No. } \\
\text { W HOI-88-2 }\end{array}$ \\
\hline \multicolumn{2}{|c|}{$\begin{array}{l}\text { 9. Performing Organization Name and Address } \\
\text { Woods Hole Oceanographic Institution } \\
\text { Woods Hole, Massachusetts } 02543 \\
\text { (* McKeldin Library, University of Maryland } \\
\text { College Park, Maryland 20742) }\end{array}$} & $\begin{array}{l}\text { 10. Project/Task/Work Unit No. } \\
\text { 11. Contract(C) or Grant(G) No. } \\
\text { (C) } \\
\text { (G) }\end{array}$ \\
\hline \multicolumn{2}{|c|}{$\begin{array}{l}\text { 12. Sponsoring Organization Name and Address } \\
\text { The Marine Mammal Commission, and The National Marine } \\
\text { Fisheries Service }\end{array}$} & $\begin{array}{l}\text { 13. Type of Report \& Period Covered } \\
\text { Technical } \\
\text { 14. }\end{array}$ \\
\hline
\end{tabular}

15. Supplementary Notes

This report should be cited as: Woods Hole Oceanog. Inst. Tech. Rept., WHOI-88-2.

16. Abstract (Limit: 200 words)

A comprehensive Reference Database has been designed for the marine mammal literature. The system uses INMAGIC programming (Cambridge, MA) to file, store, search, retrieve, and format the data records. The database was organized to be complementary to features developed by William E. Schevill for his library of older cetacean literature, and it uses direct association of species with some 300 indexed subjects, observation dates, locations, etc. Every component and detail of the references and annotations are available for rapid search by a wide variety of simple and complex strategies. In addition, separately indexed fields provided immediate retrieval of author, editor, year, journal, type of publication, language, genus/species (searchable by order/ suborder and family as well), major subject, subject, picture, observation date, geographic location (including area name and latitude/longtitude), as well as the location and library call numbers of the document referred to. Codes have been adapted for ease in identifying and searching species, subjects, journals, languages, and geographic areas. These codes may be used separately or in connection with the associated terms and texts. It is anticipated that the Reference Database will be a continuing resource for marine mammal research.

17. Document Analysis a. Descriptors

1. marine mammal literature

2. reference database

b. Identifiers/Open-Ended Terms

c. COSATI FIEld/Group

18. Availability Statemen:

Approved for publication; distribution unlimited.

\begin{tabular}{|l|l|}
\hline $\begin{array}{l}\text { 19. Security Class (This Report) } \\
\text { UNCLASSIFIED }\end{array}$ & $\begin{array}{c}\text { 21. No. of Pages } \\
82\end{array}$ \\
\hline 20. Security Class (This Page) & 22. Price \\
\hline
\end{tabular}

